\title{
Flexural and Axial Strengthening of Preloaded Concrete Columns under Large Eccentric Loads by Flat and Precambered Steel Plates
}

\author{
R. K. L. Su ${ }^{a^{*}}$ and L. Wang ${ }^{b}$ \\ ('. Department of Civil Engineering, The University of Hong Kong, Pokfulam Road, Hong Kong)

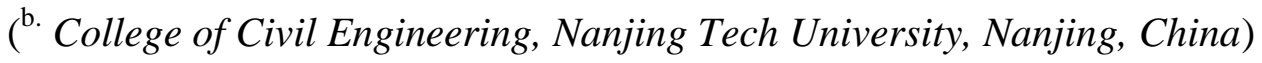

In this study, the behaviour of the preloaded RC columns under large eccentric compression loading and strengthened with flat and precambered steel plates was investigated. An original analytical model considering the effects of stress-lagging induced by eccentric pre-compressed loading was developed to predict the ultimate load capacity of plate-strengthened columns. Then ten specimens with different eccentricities, plate thicknesses and initial precamber displacements were tested. The strength, deformability, ductility and moment-curvature response of the strengthened columns were examined, and the effectiveness of this approach was validated. The good agreement between the analytical and experimental results demonstrates that the proposed analytical model can accurately predict the load-carrying capacity of the plate-strengthened columns under large eccentric compression loading.

Keywords: Reinforced concrete columns; precambered steel plates; strengthening; eccentricity; ductility

*Corresponding author. E-mail: klsu@hkucc.hku.hk. 


\section{Introduction}

External FRP jacketing and steel jacketing are the main strengthening approaches for upgrading RC columns. In the past one decade, Lam and Teng (2003a; 2003b), Teng and Jiang (2007), Teng et al. (2009), Wei and Wu (2012) and Wu and Jiang (2013) proposed a series of the stress-strain relationship of FRP-confined columns. Meanwhile, a large number of experimental and Analytical researches on the behaviour of the FRP wrapped RC columns under eccentric compression loading have already been conducted (Teng et al. 2003, Wu et al. 2006, Hadi and Li 2004, Hadi 2006a; 2006b; 2007a; 2007b; 2009, El Maaddawy 2008a; 2008b; 2009, Pellegrino and Modena 2010, Hu et al. 2011, Quiertant and Clement 2011, Sadeghian et al. 2010, Song 2013).

In terms of steel jacketing, extensive experimental and theoretical studies have also been conducted (Frangou et al. 1995, Ramirez 1996, Cirtek 2001a, 2001b, Giménez et al. 2009a, 2009b, Adam et al. 2007, 2009a, 2009b, Calderon et al. 2009, Yang and Ashour 2007, Yang et al. 2009,). However, only a few studies involved strengthening these columns by steel jacketing under eccentric compression loading. Li et al. (2009) studied the behaviour of concrete columns strengthened with steel angles and fibre-reinforced polymer (FRP) sheets under combined lateral cyclic displacement excursions and constant axial load. Their results demonstrated that composite wraps could increase the strength and ductility of columns. Garzón et al. (2011a; 2011b) tested a series of RC columns strengthened by steel strips and angles under combined bending and axial loading. They indicated that this strengthening method can enhance the load resistance and ductility of strengthened columns. Furthermore, to increase the strength in the zone nearest to the beam-column joints, two different types of elements, capitals welded to the steel cage and steel tubes joining the steel cage, were proposed. Montuori and Piluso (2009) tested thirteen RC columns strengthened by steel angles and battens under eccentric loading conditions. Their study indicated that both the axial load-carrying capacity and the lateral deformability of strengthened concrete columns were improved. Furthermore, they proposed a analytical model that was able to predict the load-carrying capacity of the strengthened columns based on a kinematic mechanism. 
However, no matter which jacket is used to strengthen preloaded RC columns, a few studies have considered the effects of stress-lagging between the original concrete core and the new jackets. Ersoy et al. (1993), Takeuti et al. (2008) and Giménez et al. (2009b) found that stress-lagging effects could significantly decrease the ultimate axial load capacity of the strengthened columns. To address this stress-lagging problem, Su and Wang (2012) and Wang and Su (2013b, 2014) proposed a column decompression approach to strengthen preloaded RC columns under axial compression loading. In this approach, precambered steel plates were installed on two faces of an RC column. Flattening the plates can generate a post-compressive force in the steel plates and create a decompressive force of equal magnitude in the RC column. Hence, preloading can be resisted by both the RC column and the steel plates. Compared with the other strengthening methods, such as FRP jacketing, concrete jacketing and pasting steel plates on the concrete, using this method the steel plates can actively share the existing loads with the original column. Stress relief in the original column and post-stress developed in the steel plates can reduce stress-lagging and displacement incompatibility problems. The test results demonstrated that the decompression approach was effective in reducing the stress in the original column and increasing the axial load-carrying capacity of strengthened columns.

Wang and Su (2012, 2013a) expanded the decompression approach to strengthen preloaded RC columns under eccentric loading. In this study, the additional precambered steel plates were placed on the side faces of the RC column, which were perpendicular to the applied moment axis, as shown in Figure 1a. All the strengthened columns were subjected to eccentric pre-compressed loading before the precambered steel plates were installed. The test results proved that the ultimate load capacity of the strengthened column was drastically affected by the eccentricity. The ultimate load capacity of the column did not significantly improve when the eccentricity was larger than that corresponding to the balance failure (Wang and $\mathrm{Su}$ 2012). In their studies, compared to the control column, the ultimate load capacity of the strengthened RC column can be increased by $64.0 \%$ when the eccentricity was less than that of the balance failure, but the ultimate load capacity of the strengthened RC column just can be increased by $23.9 \%$ when the eccentricity was larger than that of the balance failure. The 
reason is that flattening the precambered steel plates can significantly increase the tensile stress in the concrete core during the post-stressed stage under the large eccentric compression loading. The high tensile stress could accelerate the column failure. Therefore, to address this shortcoming, a new decompression approach is presented herein to improve the ultimate load capacity of columns subjected to large eccentricity loads. In this approach, the columns were still strengthened with precambered steel plates; however, the flat and precambered steel plates were placed on the tension and compression sides of the RC column, respectively, as shown in Figure 1b. Furthermore, the decompression method was only applied to the compression side.

In this paper, according to the proposed strengthening approach, an original analytical model was developed considering the effects of stress-lagging to predict the ultimate load capacity of the platestrengthened columns. Then an experimental verification was also conducted. The strength, flexural capacity, deformability and ductility of the strengthened RC columns were reported. Finally, the accuracy of the analytical model was validated by comparing the analytical results with available test results of Montuori and Piluso (2009). Based on the comprehensive analytical and experimental results, this paper attempts to establish an innovative strengthening approach to aid engineers in upgrading preloaded RC columns, bridge piers, shear walls and so on.

\section{Analytical model}

\section{Initial precamber and material constitutive laws}

As shown in Figure 2a, in order to control the initial precamber $(\delta)$ for specimens, a stainless steel rod with a diameter equal to $\delta$ was inserted between the concrete and steel plate in the middle height of the column. The bolts were then tightened at both ends of the column to form the desired initial precamber profile (Figure $2 \mathrm{~b}$ ). Because the end rotations of the steel plates are restrained by the bolts at both ends of the plates, the initial lateral displacement $(v)$ of the precambered plate can be approximated by a cosine function (Figure 2c), which is expressed in Equation 1 ( $\mathrm{Su}$ and Wang 2012). 


$$
v=\frac{\delta}{2}\left[1-\cos \left(\frac{2 \pi x}{L_{r c, p l}}\right)\right]
$$

where $\delta$ is the initial precamber at the mid-height of the plate; $L_{r c, p l}$ is the clear height of the RC column under preloading $\left(P_{p l}\right) ; x$ is the coordinate defined along the height of the column; and the subscript $p l$ denotes the preloading stage. Equation 1 satisfies the boundary conditions at both ends of the steel plates, i.e., $v=0$ and $\frac{d v}{d x}=0$ when $x=0$ or $x=L_{r c, p l}$.

In this model, the concrete tensile strength was ignored during the calculation. The stress-strain relationship of the concrete in compression is represented by the parabolic relationship proposed by Hognestad et al. (1955).

$$
\sigma_{c}=f_{c}\left[\frac{2 \varepsilon_{c}}{\varepsilon_{c 0}}-\left(\frac{\varepsilon_{c}}{\varepsilon_{c 0}}\right)^{2}\right]
$$

where $f_{c}$ is the compressive cylinder strength of the concrete; $\sigma_{c}$ and $\varepsilon_{c}$ are the stress and strain of the concrete, respectively; and $\varepsilon_{c 0}$ is the concrete compressive strain corresponding to $f_{c}$.

Both the steel plates and steel bars are assumed to be elasto-plastic materials. In the initial elastic stage, the stress-strain models of the steel plates and steel bars can be expressed as

$$
\begin{gathered}
\sigma_{p}=E_{p} \varepsilon_{p} \\
\sigma_{s}=E_{s} \varepsilon_{s}
\end{gathered}
$$

where $\sigma_{p}, \varepsilon_{p}$ and $E_{p}$ are the stress, the strain and the Young's modulus of the steel plates, respectively; and $\sigma_{s}, \varepsilon_{s}$ and $E_{s}$ are the stress, the strain and the Young's modulus of the steel bars, respectively.

\section{Preloading stage}

In the preloading stage, the preloading force is resisted solely by the concrete and the steel bars before the external steel plates are installed. The vertical force equilibrium equation of the RC column can be obtained from the sum of the internal forces (Park and Paulay 1975). 


$$
P_{p l}=\alpha \beta b c_{p l} f_{c}^{\prime}\left(\frac{2 \varepsilon_{c, p l}}{\varepsilon_{c 0}}-\frac{\varepsilon_{c, p l}{ }^{2}}{\varepsilon_{c 0}{ }^{2}}\right)+E_{s} A_{s c} \varepsilon_{c, p l}\left(\frac{c_{p l}-d^{\prime}}{c_{p l}}\right)-E_{s} A_{s t} \varepsilon_{c, p l}\left(\frac{d-c_{p l}}{c_{p l}}\right)
$$

The moment equilibrium equation, which was obtained by taking moments about the tension steel, is given by

$$
P_{p l} e^{\prime}=\alpha \beta b c_{p l} f_{c}^{\prime}\left(\frac{2 \varepsilon_{c, p l}}{\varepsilon_{c 0}}-\frac{\varepsilon_{c, p l}{ }^{2}}{\varepsilon_{c 0}{ }^{2}}\right)\left(d-\frac{\beta c_{p l}}{2}\right)+E_{s} A_{s c} \varepsilon_{c, p l}\left(\frac{c_{p l}-d^{\prime}}{c_{p l}}\right)\left(d-d^{\prime}\right)
$$

where $b$ is the width of the column section, as shown in Figure 3; $d$ and $d$ are the depths of the tension steel bars and the compression steel bars, respectively, measured from the extreme compression fibre. $A_{s c}$ and $A_{s t}$ are the total cross-sectional areas of the compression steel bars and the tension steel bars, respectively; $e^{\prime}$ is the distance between the loading point and the tension steel bars. $\alpha$ and $\beta$ are stress block factors of concrete stress distribution (Figure 3). The values can be determined by Equation 7 and Equation 8 (Collins and Mitchell 1987). The depth of the compression zone $\left(c_{p l}\right)$ and the concrete strain at the extreme compression fibres $\left(\varepsilon_{c, p l}\right)$ in the preloading stage can be obtained from Equations 5 to 8.

$$
\begin{aligned}
& \alpha=\left[\frac{\varepsilon_{c u}}{\varepsilon_{c 0}}-\frac{1}{3}\left(\frac{\varepsilon_{c u}}{\varepsilon_{c 0}}\right)^{2}\right] / \beta \\
& \beta=\left(4-\frac{\varepsilon_{c u}}{\varepsilon_{c 0}}\right) /\left(6-\frac{2 \varepsilon_{c u}}{\varepsilon_{c 0}}\right)
\end{aligned}
$$

The height of the RC column $\left(L_{r c, p l}\right)$ at the compression side under the preloading can be expressed as (Gere and Timoshenko 1990)

$$
L_{r c, p l}=2\left(R_{p l}-c_{p l}\right) \sin \left(\frac{L_{n a}}{2 R_{p l}}\right)
$$

where $L_{n a}$ is the height of the RC column at the neutral axis position. $R_{p l}$ is the radius of curvature of the RC column under the preloading (Figure 4a), which can be calculated by Equation (10).

$$
R_{p l}=\frac{1}{\varphi_{p l}}=\frac{c_{p l}}{\varepsilon_{c, p l}}
$$

where $\varphi_{p l}$ is the curvature of the RC column under the preloading. 


\section{Post-stressing stage}

In the post-stressing stage, a precambered steel plate and a flat steel plate are installed on the compression and tension sides of the RC column under the preloading, and the decompression method is applied only to the plate on the compression side. During the post-stressed process, the flat steel plate does not provide any resistance to the RC column because the bolts connecting the steel angles and concrete have not been fastened. When the precambered steel plate is flattened, a postcompressive force $\left(P_{p c, p s}\right)$ is generated in the steel plate, and a decompressive force of equal magnitude is developed in the RC column. The height of the RC column $\left(L_{r c, p s}\right)$ at the compression side after the flattening of the plate can be obtained by Equation (11) (Figure 4b).

$$
L_{r c, p s}=2\left(R_{p s}-c_{p s}\right) \sin \left(\frac{L_{n a}}{2 R_{p s}}\right)
$$

where $R_{p s}$ is the radius of curvature of the RC column after the flattening of the plate; and the subscript ps denotes the post-stressing stage. The radius of curvature can be calculated by following Equation

$$
R_{p s}=\frac{1}{\varphi_{p s}}=\frac{c_{p s}}{\varepsilon_{c, p s}}
$$

where $\varphi_{p s}$ is the curvature of the RC column when the precambered steel plate is flattened. $c_{p s}$ and $\varepsilon_{c, p s}$ are the depth of the compression zone and strain of the concrete in the post-stressing stage, respectively.

By considering the displacement compatibility of the steel plate and the RC column on the compression side, the plate axial shortening $\left(\Delta_{p c, p s}\right)$ and the plate compressive strain $\left(\varepsilon_{p c, p s}\right)$ in the poststressing stage can be estimated by Equation (13) and Equation (14), respectively (see Figure 5).

$$
\begin{gathered}
\Delta_{p c, p s}=L_{r c, p l}+\Delta_{L}-L_{r c, p s} \\
\varepsilon_{p c, p s}=\frac{\Delta_{p c, p s}}{L_{r c, p l}+\Delta_{L}}
\end{gathered}
$$


where $\Delta_{L}$ is the difference in the length of the steel plate and the RC column. According to the approximate precambered profile described in Equation (1), $\Delta_{L}$ is found to be ( $\mathrm{Su}$ and Wang 2012)

$$
\Delta_{L}=\frac{(\pi \delta)^{2}}{4 L_{r c, p l}}
$$

After flattening the precambered steel plate, the vertical force, and the moment equilibrium equations become

$$
\begin{gathered}
P_{p l}=\alpha \beta b c_{p s} f_{c}^{\prime}\left(\frac{2 \varepsilon_{c, p s}}{\varepsilon_{c 0}}-\frac{\varepsilon_{c, p s}{ }^{2}}{\varepsilon_{c 0}{ }^{2}}\right)+E_{s} A_{s c} \varepsilon_{c, p s}\left(\frac{c_{p s}-d^{\prime}}{c_{p s}}\right)-E_{s} A_{s t} \varepsilon_{c, p s}\left(\frac{d-c_{p s}}{c_{p s}}\right)+E_{p c} A_{p c} \varepsilon_{p c, p s} \\
P_{p l} e^{\prime}=\alpha \beta b c_{p s} f_{c}^{\prime}\left(\frac{2 \varepsilon_{c, p s}}{\varepsilon_{c 0}}-\frac{\varepsilon_{c, p s}{ }^{2}}{\varepsilon_{c 0}{ }^{2}}\right)\left(d-\frac{\beta c_{p s}}{2}\right)+E_{s} A_{s c} \varepsilon_{c, p s}\left(\frac{c_{p s}-d^{\prime}}{c_{p s}}\right)\left(d-d^{\prime}\right)+E_{p c} A_{p c} \varepsilon_{p c, p s}\left(\frac{t_{p c}}{2}+d\right)
\end{gathered}
$$

where $E_{p c}, A_{p c}$ and $t_{p c}$ are Young's modulus, the cross-sectional area and the thickness of the precambered steel plate, respectively.

The strain of the precambered steel plate $\left(\varepsilon_{p c, p s}\right)$, the depth of the compression zone $\left(c_{p s}\right)$ and the strain of the concrete $\left(\varepsilon_{c, p s}\right)$ in the post-stressing stage can then be obtained by solving Equations (7) to (17).

The decompressive force $\left(P_{p c, p s}\right)$ is controlled by the initial precamber of the steel plate. With the increase of the initial precamber, the decompressive force in the RC column increases. If the occurrence of a reversed moment in the RC column has to be avoided, the magnitude of the decompressive force should satisfy Equation (18).

$$
P_{p c, p s}\left(\frac{t_{p c}}{2}+d\right) \leq P_{p l} e^{\prime}
$$

Substituting Equations (11) to (15) into Equation (18) gives,

$$
\delta \leq \frac{4}{\pi} \sqrt{\frac{P_{p l} e^{\prime}\left(\frac{c_{p l}}{\varepsilon_{c, p l}}-c_{p l}\right) \sin \left(\frac{L_{n a} \varepsilon_{c, p l}}{2 c_{p l}}\right)\left(\frac{c_{p s}}{\varepsilon_{c, p s}}-c_{p s}\right) \sin \left(\frac{L_{n a} \varepsilon_{c, p s}}{2 c_{p s}}\right)}{P_{p l} e^{\prime}-E_{p c} A_{p c}\left(\frac{t_{p c}}{2}+d\right)}-\left(\frac{c_{p l}}{\varepsilon_{c, p l}}-c_{p l}\right)^{2} \sin ^{2}\left(\frac{L_{n a} \varepsilon_{c, p l}}{2 c_{p l}}\right)}
$$




\section{Ultimate load capacity}

Assuming that the compression steel plate has yielded, the equilibrium equations can be obtained, from the sum of the internal forces, and from taking moments about the tension steel,

$$
\begin{gathered}
P_{p r e}=\alpha \beta b c_{u} f_{c}^{\prime}+A_{s c} f_{s c y}-A_{s t} f_{s t}+A_{p c} E_{p c} \varepsilon_{p c}-A_{p t} f_{p t} \\
P_{p r e} e^{\prime}=\alpha \beta b c_{u} f_{c}^{\prime}\left(d-\frac{\beta c_{u}}{2}\right)+A_{s c} f_{s c y}\left(d-d^{\prime}\right)+A_{p c} E_{p c} \varepsilon_{p c}\left(d+\frac{t_{p c}}{2}\right)+A_{p t} f_{p t}\left(h-d+\frac{t_{p t}}{2}\right)
\end{gathered}
$$

where $f_{s c y}$ is the yield strength of compression steel bars; $f_{s t}$ is the stress in the tension steel bars; $t_{p t}$ is the thickness of the flattened steel plate; $f_{p t}$ is the stress in the tension steel plate; $A_{p t}$ is the crosssectional area of the flattened steel plate; and $h$ is the depth of the RC column (Figure 3); ); $\varepsilon_{p c}$ is the strain of precambered steel plate, which can be determined by following equation

$$
\varepsilon_{p c}=\left\{\begin{array}{cc}
\varepsilon_{c u}-\varepsilon_{c, p s}+\varepsilon_{p c, p s} & \left(\varepsilon_{c u}-\varepsilon_{c, p s}+\varepsilon_{p c, p s}<\varepsilon_{p c y}\right) \\
\varepsilon_{p c y} & \left(\varepsilon_{c u}-\varepsilon_{c, p s}+\varepsilon_{p c, p s} \geq \varepsilon_{p c y}\right)
\end{array}\right.
$$

The stress in the tension steel bar $\left(f_{s t}\right)$ and the tension steel plate $\left(f_{p t}\right)$ can be calculated by

$$
\begin{gathered}
f_{s t}=E_{s} \varepsilon_{s c y} \frac{d-c_{u}}{c_{u}-d^{\prime}} \\
f_{p t}=E_{p t} \varepsilon_{p c}\left(\frac{h-c_{u}+\frac{t_{p t}}{2}}{c_{u}+\frac{t_{p c}}{2}}\right)
\end{gathered}
$$

The depth of the compression zone $\left(c_{u}\right)$ and the ultimate load-carrying capacity $\left(P_{\text {pre }}\right)$ are obtained from Equations (20) to (24). If a tension failure occurs, the tension steel bars yield. Equation (20) is still valid by replacing $f_{s t}$ with the yield strength $f_{\text {sty }}$ of the tension steel bars.

\section{The maximum bolt spacing}

To prevent local buckling of the steel plates so that plate yielding can occur, the plate buckling load should be higher than the designed axial force in the steel plate. Hence,

$$
P_{p, c r}>A_{p c} E_{p c} \varepsilon_{p c}
$$

where $P_{p, c r}$ is the critical load of the steel plate which can be calculated by the Euler equation as 


$$
P_{p, c r}=\frac{\pi^{2} E_{p c} I_{p c}}{\left(\mu s_{\max }\right)^{2}}
$$

where $s_{\max }$ is the maximum bolt spacing and $\mu$ is a factor related to the boundary conditions for the columns. In the present case, as both ends of the steel plates were clamped, $\mu$ is equal to 0.5 (Timoshenko and Gere 1961).

The maximum bolt spacing for preventing local plate buckling can be determined by using Equations (25) and (26).

\section{Experimental program}

\section{Test specimens}

In this study, ten specimens were fabricated and tested. All specimens had the same dimensions with a clear column height $\left(L_{r c}\right)$ of $600 \mathrm{~mm}$ and a uniform cross section of $150 \mathrm{~mm} \times 100 \mathrm{~mm}$. The $4 \mathrm{~T} 10$ vertical steel bars were arranged, and a transverse reinforcement of R6 was adopted, where $T$ and $R$ denote the high-yield deformed bars and the mild steel round bars respectively. The yield strength of T10 and R6 are $495 \mathrm{MPa}$ and $464 \mathrm{MPa}$, respectively. The Young's modulus of T10 and R6 are 197 GPa and $186 \mathrm{GPa}$, respectively. To prevent local failure, both ends of the column were enlarged and heavily reinforced. The reinforcement details are shown in Figure 6.

All specimens were divided into three groups in accordance with the degrees of eccentricity (Group A, $e=60 \mathrm{~mm}$; Group B, $e=100 \mathrm{~mm}$; Group C, $e=140 \mathrm{~mm}$ ). Specimens MSC1-1, MSC2-1 and MSC3-1 were control columns without any strengthening measures to demonstrate the structural performance of RC columns prior to strengthening. The rest of specimens were strengthened by precamber steel plates with varying initial precamber $(\delta)$ and thickness of the tension plate $\left(t_{p t}\right)$ and compression plate $\left(t_{p c}\right)$. All strengthened columns were subjected to a preloading before the steel plate on the compression side was flattened, which was equal to $30 \%$ of the ultimate load capacity of the corresponding control column. For the plate-strengthened specimens, the axial load was applied under a force control with a loading rate of $2 \mathrm{kN}$ per second. After tightening the bolts and flattening the 
precambered plate, the applied load was changed to a displacement control with a displacement rate of $0.5 \mathrm{~mm}$ per minute. The test was terminated when the post-peak load reached $75 \%$ of the peak load. The design parameters, the preload and the compressive strength of the concrete cylinder $\left(f_{c}\right)$ are summarised in Table 1 for all specimens. The material properties of the steel reinforcements and steel plates are summarised in Table 2.

\section{Test set-up and instrumentation}

Figures 7(a) and (b) show the test set-up. The tests were conducted in the Structural Engineering Laboratory at the University of Hong Kong. Loading was applied by a hydraulic actuator with an axial capacity of $1000 \mathrm{kN}$. The loading device, consisted of roller, adaptor and cap, was shown in Figure 7(c). The designed channels engraved on the cap, which determined the degree of eccentricity. Two LVDTs with a stroke of $25 \mathrm{~mm}$ were set at tension side and compression side of the column vertically to measure the axial deformations of columns; another LVDT with $25 \mathrm{~mm}$ was placed at the middle height of the column horizontally to obtain the lateral deformation. In each specimen, strains in the longitudinal reinforcements and the steel plates were measured using electrical resistance linear strain gauges. The strain gauges were attached to the steel plates in four different sections along the height and in the middle of vertical steel bars to investigate the deformations and internal stress distributions of the steel plates. According to the strain gauge readings, the decompressive forces in the steel plates were calculated. Then the effects of camber deflection were monitored by comparing the measured and Analytical forces. Figure 8 shows the arrangement of LVDT and strain gauges. The strain readings were also used to identify the failure mode.

\section{Post-stress procedure}

To avoid warping or buckling of the steel plates during the decompression process, a unified poststress procedure is proposed, as shown in Figure 9(a). To increase the critical buckling load of the plates and prevent the warping effects, precambered plates were pressed to form high-order buckling 
modes, instead of the first-order buckling mode, during the post-stress procedure. The process can be divided into the following steps: (i) The compressed steel plate is fixed, and the bolts are tightened at the upper end of the columns while the other bolts are loosened before reaching the preloading level; (ii) bolts and tensioned steel plates that are installed at both ends of the columns are tightened when the specimen is under the preloading level. In order to make the steel plates reach their full resistance, the gaps between the steel angles and the concrete in the base and at the top of the steel plates were filled with an injection plaster to form a layer of bedding between the steel angles and the concrete. The injection plaster was composed of gypsum, potassium sulphate and water with a proportion of $37.5: 1$ : 15 by weight ( $\mathrm{Su}$ and Wang 2012). The compressive strength of the plaster can be determined by the decompressive force in the steel plate. According to the value of the decompressive force obtained from Equation 14, the plaster with around $18 \mathrm{MPa}$ compressive strength is selected. Potassium sulphate was added to the injection plaster to reduce the setting and hardening time of the gypsum. Using this proportion, the setting time and hardening time were approximately $120 \mathrm{sec}$ and $340 \mathrm{sec}$, respectively; (iii) the bolts at the mid-height are tightened; thus, the buckling mode of the precambered plate is changed to the higher modes; (iv) the plates are flattened by tightening the rest of the bolts (v \& vi) to achieve a more evenly distributed internal stress in the plates all of the bolts are slightly loosened and fastened again, then the concrete compressive strain after flattening the precambered plate becomes smaller, as shown in Figure 9(b); and (vii) the tensioned steel plate is fixed between the steel angles and the concrete by bolts, and the gaps between the steel angles and the concrete are filled with plaster before increasing the loads.

\section{Test results and evaluation}

All the test results, including the mid-span horizontal deflection $\left(\zeta_{u}\right)$, the primary moment $\left(M_{p}\right)$, the secondary moment due to $P-\Delta$ effect $\left(M_{S}\right)$, ultimate moment at the mid-height of the column $\left(M_{u}\right)$, the experimental ultimate load capacity $\left(P_{\text {exp }}\right)$, the predicted ultimate load capacity $\left(P_{\text {pre }}\right)$ and the maximum strain of steel plate under peak loading $\left(\varepsilon_{p, p e a k}\right)$, are summarized in Table 3 . The failure 
mode of specimens in Group A is compression failure because the degree of eccentricity is less than that of the balance failure, while the failure mode of specimens in Group B and Group C is tension failure.

\section{Strength analysis}

Compared with the control column in each of the groups, the strengthened specimens show various degrees of strengthening from $65.1 \%$ to $122.4 \%$, which are summarised in Table 3 . In Group A, the ultimate load capacity of Specimens MSC1-2 and MSC1-3 are increased by $78.4 \%$ and $65.1 \%$. In Group B, the ultimate load capacities of Specimens MSC2-2, MSC2-3, MSC2-4 and MSC2-5 are enhanced by $66.4 \%, 106.3 \%, 122.4 \%$ and $88.8 \%$, respectively. In Group C, the ultimate load capacity of Specimens MSC3-2 is increased by $121.4 \%$.

Figure 10 illustrates the effects of eccentricity on the performance of columns. According to Figure 10a, for the control columns, the ultimate load capacity of Specimen MSC1-1 under $60 \mathrm{~mm}$ eccentricity was $218 \mathrm{kN}$. The value was $52.4 \%$ and $144.9 \%$ larger than the ultimate load capacity of Specimen MSC2-1 under $100 \mathrm{~mm}$ and Specimen MSC3-1 under $140 \mathrm{~mm}$ eccentricity, respectively. According to Figure 10b, compared to the other two specimens, the ultimate load capacity of Specimen MSC1-2 was the largest $(389 \mathrm{kN})$ due to the smallest eccentricity $(60 \mathrm{~mm})$, which was $16.8 \%$ larger than the ultimate load capacity of Specimen MSC2-4 under $100 \mathrm{~mm}$ eccentricity and $66.2 \%$ larger than the ultimate load capacity of Specimen MSC3-2 under $140 \mathrm{~mm}$ eccentricity. The results prove that the performance of the column is mainly affected by the eccentricity, and a smaller eccentricity can give a higher ultimate load capacity.

Figure 11 shows the effects of plate thickness on the ultimate load capacity $\left(P_{\text {exp }}\right)$ under the same preloading level and initial precamber. In Group A, compared to Specimen MSC1-2 $\left(t_{p c}=6 \mathrm{~mm} ; t_{p t}=6\right.$ $\mathrm{mm})$, the ultimate load capacity of Specimen MSC1-3 $\left(t_{p c}=6 \mathrm{~mm} ; t_{p t}=3 \mathrm{~mm}\right)$ decreased by $8.1 \%$, as shown in Figure 11a. In Group B, compared to Specimen MSC2-4 ( $\left.t_{p c}=6 \mathrm{~mm} ; t_{p t}=6 \mathrm{~mm}\right)$, the ultimate load capacity and deformability of Specimens MSC2-2 $\left(t_{p c}=3 \mathrm{~mm} ; t_{p t}=3 \mathrm{~mm}\right)$ and MSC2-5 $\left(t_{p c}=6 \mathrm{~mm}\right.$; $t_{p t}=3 \mathrm{~mm}$ ) decreased by $40.0 \%$ and $21.1 \%$, respectively, as shown in Figure $11 \mathrm{~b}$. The results 
demonstrate that the use of thicker plates can enhance both the strength and deformability of platestrengthened columns.

Figure 12 shows the effects of initial precamber $(\delta)$ on the ultimate load capacity. The ultimate load capacity of Specimen MSC2-4 with $\delta=10 \mathrm{~mm}$ was $333 \mathrm{kN}$, being $12.9 \%$ larger than the ultimate load capacity of Specimen MSC2-3 with $\delta=6 \mathrm{~mm}$. Because the increase of initial precamber could generate greater post-compressive stress in the steel plates, more loading in the original RC column could be transferred to the steel plates. Therefore, increasing $\delta$ by using steel plates with a larger initial precamber leads to greater compression load sharing and a higher ultimate load capacity.

Due to the eccentricity of the applied axial load, a bending moment is always generated. The ultimate moment $\left(M_{u}\right)$ at the mid-height of the column is composed of the primary moment $\left(M_{p}\right)$ calculated based on the nominal eccentricity and the secondary moment $\left(M_{s}\right)$ caused by the $P-\Delta$ effect, which are summarised in Table 3. The definitions of the primary, secondary and ultimate moments can be calculated by Equations (27)-(29) (Wang and $\mathrm{Su} 2012$ ).

$$
\begin{gathered}
M_{p}=P \times e \\
M_{s}=P \times \zeta_{u} \\
M_{u}=M_{p}+M_{s}
\end{gathered}
$$

In Group A, the secondary moment of the strengthened columns MSC1-2 and MSC1-3 due to the $P-\Delta$ effect increased by $58.3 \%$ and $55.3 \%$, respectively. In Group B, the secondary moment of the strengthened column due to the $P-\Delta$ effect increased by $97.2 \%, 239.3 \%, 237.2 \%$ and $159.3 \%$. In Group $\mathrm{C}$, the secondary moment of the strengthened column due to the $P-\Delta$ effect increased by $327.1 \%$.

In the previous studies (Wang and Su, 2012a \& 2012b), the authors tested two RC columns (Specimens ESC3-2 and ESC3-3) strengthened with precambered steel plates installed on the side faces of the column under eccentric compression loading with an eccentricity of $100 \mathrm{~mm}$. The 
Specimens ESC3-2, ESC3-3, MSC2-2 and MSC2-4 had the same dimensions, reinforcement arrangements, preloading level and precamber displacement. Compared with the ultimate load capacity of Specimen ESC3-2 which was strengthened with $3 \mathrm{~mm}$ thick plates $\left(P_{u}=158 \mathrm{kN}\right)$, the ultimate load capacity of Specimen MSC2-2 increased by 50.6\%. Compared with the ultimate load capacity of Specimen ESC3-3 which was strengthened with $6 \mathrm{~mm}$ thick plates $\left(P_{u}=213 \mathrm{kN}\right)$, the ultimate load capacity of Specimen MSC2-4 increased by 56.3\%. It is evident that placing flat and precambered steel plates on the tension and compression sides respectively of the RC column and using decompression method on the compression side can significantly improve the ultimate axial and flexural capacities of RC columns, especially under large eccentricity.

\section{Crack patterns and failure modes}

The strain gauges attached on the steel plates were used to investigate the deformation of steel plates and the failure modes of the columns. For each column, the maximum recorded strains at the peak load are shown in Table 3. The recorded strains indicated that all steel plates did not yield at the peak loading stage. The concrete crack patterns and failure modes of the test specimens in each group were quite similar. For the specimens in Group A, the initial concrete cracks usually occurred at the midheight of the columns on the compression side and then propagated in the vertical direction. With an increasing applied load, the major cracks were extended and the concrete was spalled, as shown in Figure 13a. The failure mode was the crushing of concrete on the compression side, during which the tension reinforcements did not yield. For Group B and Group C, the initial concrete cracks usually occurred at the mid-height of the columns on the tension side and then extended in the horizontal direction. As the applied load increased, the major cracks were extended, and vertical cracks were then formed on the compression side, as shown in Figure 13b. The failure mode was the yielding of tension steel followed by the crushing of concrete on the compression side. 


\section{Load-longitudinal strain relationship}

Figure 14 shows the relationship between the applied load and the longitudinal strains of reinforcement bars in specimens. The changes in longitudinal strains of control columns are reflected in Figure 14a under different eccentricities, and the changes in longitudinal strains of strengthened columns with 6-mm-thick plates under different eccentricities are shown in Figure 14b. It is evident that the longitudinal strain changed with increasing eccentricity. The compression steel reinforcements yielded when the specimens in Group A reached the ultimate load capacity, while the tension steel reinforcement did not yield $\left(\varepsilon_{s t}=0.0013\right.$ for MSC1-1 and $\varepsilon_{s t}=0.0007$ for MSC1-2). For the specimens in Group B and Group C, the tension steel reinforcement yielded during failure due to the large eccentricity. Hence, the failure mode of steel reinforcements were determined by the degree of eccentricity. The compression steel reinforcements yielded firstly when the degree of eccentricity was less than that of balance failure, otherwise the tension steel reinforcements reached their yield point firstly.

Figure $14 \mathrm{c}$ shows the effects of plate thickness on the longitudinal strains. The steel reinforcement tension strain of Specimens MSC2-2 and MSC2-5 were larger than that of Specimen MSC2-4 under the same applied load, which was due to the fact that Specimens MSC2-2 and MSC2-5 were strengthened with 3-mm-thick tension plates, while Specimen MSC2-4 was strengthened with 6-mmthick tension plates. It is found that the thicker tension plates could share a greater tension load from the original RC column, hence tension strain in the steel reinforcement of Specimen MSC2-4 could be reduced.

Figure $14 \mathrm{~d}$ shows the effects of the initial precamber on the compression strains. The compression strain of steel reinforcement of Specimen MSC2-3 $(\delta=6 \mathrm{~mm})$ was larger than that of Specimen MSC2-4 $(\delta=10 \mathrm{~mm})$ under the same compression load, which resulted from the differential in the initial precamber. When the precambered steel plate was flattened, the steel plate with larger initial precamber height can provide more resistance to the applied load, which can diminish the strain in the 
compression steel reinforcements. Hence, compression strain of steel reinforcement of Specimen MSC2-4 was smaller than that of Specimen MSC2-3.

\section{Moment-curvature responses}

Figure 15a displays the effects of eccentricity on the moment-curvature relationship of the columns. For the specimens strengthened by $6 \mathrm{~mm}$ plates, the moment-curvature relationship of Specimen MSC3-2 under $140 \mathrm{~mm}$ eccentricity was elastic until the moment reached $29.8 \mathrm{kNm}$, which was $36.7 \%$ and $3.8 \%$ larger than that of Specimen MSC1-2 under $60 \mathrm{~mm}$ eccentricity and Specimen MSC2-4 under $100 \mathrm{~mm}$ eccentricity. MSC3-2 failed when the curvature was $67.3 \times 10^{-3} \mathrm{~m}^{-1}$, which was $32.0 \%$ and $21.3 \%$ larger than that of Specimens MSC1-2 and MSC2-4.

Figure $15 \mathrm{~b}$ shows the effects of the initial precamber on the moment-curvature relationship of the columns. The moment-curvature relationship of Specimen MSC2-4 with $10 \mathrm{~mm}$ initial precamber was elastic until the moment reached $28.7 \mathrm{kNm}$, which was $7.8 \%$ larger than that of Specimen MSC2-3 with $6 \mathrm{~mm}$ initial precamber. Both of them had the same curvature during the elastic stage. Specimen MSC2-4 failed when its curvature was $55.5 \times 10^{-3} \mathrm{~m}^{-1}$, which was $7.8 \%$ larger than that of Specimen MSC2-3.

Figure $15 \mathrm{c}$ and $\mathrm{d}$ show the effects of the plate thickness on the moment-curvature relationship of the columns. Under the condition of $60 \mathrm{~mm}$ eccentricity, the moment-curvature relationship of Specimen MSC1-2 strengthened by the 6-mm-thick plates on the compression and tension sides was elastic until the moment and curvature reached $21.8 \mathrm{kNm}$ and $27.9 \times 10^{-3} \mathrm{~m}^{-1}$, respectively. The corresponding values were $11.8 \%$ and $27.6 \%$ larger than the moment and curvature of Specimen MSC1-3 strengthened by the 6-mm-thick plate on the compression side and 3-mm-thick plate on the tension side. Under the condition of $100 \mathrm{~mm}$ eccentricity, the moment-curvature relationship of Specimen MSC2-4 strengthened by the 6-mm-thick plates on the compression and tension sides was elastic until the moment and curvature reached $28.7 \mathrm{kNm}$ and $35.2 \times 10^{-3} \mathrm{~m}^{-1}$, respectively. The corresponding values were $53.5 \%$ and $53.7 \%$ larger than the moment and curvature of Specimen 
MSC2-2 strengthened by the 3-mm-thick plates on the compression and tension sides, 37.3\% and 21.0\% larger than the moment and curvature of Specimen MSC2-5 strengthened by the 6-mm-thick plate on the compression side and 3-mm-thick plate on the tension side. The results demonstrated that the ductility of the column was mainly affected by the plate thickness rather than the eccentricity and the initial precamber, and a larger plate thickness can provide better ductility.

\section{Deformation and ductility}

The deformability factor $(\lambda)$, which is defined in Equation (30) (De Luca et al. 2011), was adopted to evaluate the deformation performance of the strengthened columns.

$$
\lambda=\Delta_{f} / \Delta_{u}
$$

where $\Delta_{u}$ is the axial shortening at the ultimate load and $\Delta_{f}$ is the axial shortening at the failure load, which is equal to $75 \%$ of the ultimate load. The deformability factors of specimens, summarised in Table 4, range from 1.11 (for Specimen MSC3-1) to 1.77 (for Specimen MSC2-4). Compared with Specimens MSC2-3 $(\delta=6 \mathrm{~mm})$, the deformability factor of Specimen MSC2-4 $(\delta=10 \mathrm{~mm})$ was increased by $29.2 \%$. Hence, the larger initial precamber can alleviate stress in the concrete and enhance the post-peak deformation effectively. Compared with Specimen MSC2-2 $\left(t_{p c}=3 \mathrm{~mm} ; t_{p t}=3\right.$ $\mathrm{mm})$, the deformability factor of Specimens MSC2-4 $\left(t_{p c}=6 \mathrm{~mm} ; t_{p t}=6 \mathrm{~mm}\right)$ and MSC2-5 $\left(t_{p c}=6 \mathrm{~mm}\right.$; $t_{p t}=3 \mathrm{~mm}$ ) were increased by $33.1 \%$ and $17.3 \%$. Thus, the plate thickness plays an important role in increasing the deformability of the strengthened columns. Compared with Specimen MSC1-3 ( $e=60$ $\mathrm{mm})$, the deformability factor of Specimen MSC2-5 (e=100 mm) was only increased by 4.7\%. Hence, the effect of eccentricity of the applied load on the deformability is smaller than that of initial precamber and plate thickness.

The displacement ductility factor $(\eta)$, which is defined in Equation (31) (Su et al. 2010), is introduced to evaluate the ductility performance of the strengthened columns.

$$
\eta=\Delta_{u} / \Delta_{y}
$$


where $\Delta_{y}$ is the yield displacement, which is defined as the intersection of the two straight lines associated with the load-deflection curves at the elastic and post-elastic stages, respectively. As tabulated in Table 4, the displacement ductility factors range from 1.36 (for Specimen MSC2-1) to 1.99 (for Specimen MSC1-2). For each of the groups, the displacement ductility factor of the control columns was the lowest. Compared with Specimens MSC2-3 $(\delta=6 \mathrm{~mm})$, the displacement ductility factor of Specimen MSC2-4 $(\delta=10 \mathrm{~mm})$ was increased by only $7.5 \%$. Hence, the increase in the initial precamber cannot effectively enhance the displacement ductility. Compared with Specimen $\operatorname{MSC1-3}(e=60 \mathrm{~mm})$, the displacement ductility factor of Specimen MSC2-5 $(e=100 \mathrm{~mm})$ was decreased by $8.9 \%$. Hence, the displacement ductility is not sensitive to the eccentricity of the applied load. Using thicker plates $\left(t_{p c}=6 \mathrm{~mm} ; t_{p t}=6 \mathrm{~mm}\right)$ for Specimen MSC2-4 instead of thinner plates $\left(t_{p c}=3\right.$ $\mathrm{mm} ; t_{p t}=3 \mathrm{~mm}$ ) for Specimen MSC2-2, the displacement ductility of MSC2-4 was increased by $12.3 \%$. Hence, using thicker plates can effectively improve the ductility of strengthened columns.

\section{Comparison with experimental results}

\section{Comparison with the present experimental results}

The predicted axial load capacity $\left(P_{\text {pre }}\right)$ of the specimens is presented in Table 3, which was determined by Equations (20) to (24) in the proposed analytical model. During the calculations of the ultimate load capacity of the RC columns, the strain of concrete $\varepsilon_{c 0}$ corresponding to the peak load and the extreme fibre compression strain of the concrete $\varepsilon_{c u}$ were assumed to be 0.002 (Su and Wang, 2012) and 0.003 (Park and Paulay, 1975), respectively. Comparing the analytical and experimental axial load capacities reveals that the proposed analytical model can conservatively estimate the actual axial load capacities of the plate-strengthened columns under the eccentric compression loading with an average underestimation of $1 \%$, and standard deviation is 0.05 .

\section{Comparison with available experimental results}


Table 5 compares the ultimate load capacity presented in Montuori and Piluso (2009) with the capacity obtained from the proposed analytical model. The stress-strain relationship of the confined concrete and the effective confinement area used by Montuori and Piluso (2009) were applied in our analytical calculations. For specimen D-R2, because it was tested by cutting the steel angles in tension side, just the resistance provided by steel angles in compression was considered during the calculation. For specimen D-R3, because it was tested by cutting both the steel angles in tension and in compression sides, the resistance provided by all the steel angles was ignored during the calculation. As shown in the table, all of the analytical load capacities $\left(P_{\text {pre }}\right)$ agree well with the experimental

ultimate load capacities $\left(P_{M o n, \exp }\right)$. The average discrepancy of $P_{\text {pre }} / P_{M o n, \exp }$ is only $3 \%$, and standard deviation is 0.01 . Comparing the analytical results $\left(P_{\text {Mon,pre }}\right)$ proposed by Montuori and Piluso (2009) with the analytical results obtained from our proposed model, the average discrepancy of $P_{\text {pre }} / P_{\text {Mon,pre }}$ is also $2 \%$, and standard deviation is 0.01 . Hence, the proposed analytical model is of a similar accuracy when compared with the model from Montuori and Piluso (2009).

\section{Conclusions}

This paper presents a analytical and experimental investigation on the moment strengthening RC columns using precambered steel plates under eccentric compression loading. Test results show that compared to the control column (MSC3-1), a maximum of an approximately $163 \%$ increase in the ultimate load capacity can be achieved (MSC3-2). The formulae to predict the ultimate load capacity were also proposed. The experimental and analytical results were shown to be well matched. The maximum error was 9\% (MSC2-4 and MSC3-1). The main findings of this study are summarised as follows:

(1) The experimental results show that precambered steel plates can share the existing axial load in the original column. Stress-lagging effects can be alleviated by controlling the initial precambered profile of the steel plates. 
(2) External steel plates can considerably enhance the axial and flexural strength and the deformation capacity of plate-strengthened columns under eccentric compression loading.

(3) The thicker steel plates and larger initial precamber can enhance the ultimate load capacity of columns, and the larger plate thickness can also improve the axial deformation capacity of columns significantly.

(4) The ultimate load capacity of column is affected by the degree of eccentricity. The proposed method is more effective in improving the ultimate load capacity when the eccentricity is larger than that of the balance failure.

(5) An original analytical model was developed to predict the ultimate load capacity of the platestrengthened columns under the eccentric compression loading. The experimental and Analytical results agreed well with each other. The comparison between the available test results of Montuori and Piluso (2009) and the predicted Analytical results was also presented. The comparative results demonstrate that the Analytical model can be used for designing plate-strengthened columns under large eccentric compression loading.

(6) The use of flat and precambered steel plates to strengthen the preloaded RC columns under eccentric compression loading has been demonstrated to be effective. To investigate the effectiveness and practicality of the decompression method under lateral loading, the test of RC columns strengthened using decompression method under reversed cyclic loading will be conducted in the future studies.

\section{Acknowledgements}

The research described here was supported by the Research Grants Council of the Hong Kong SAR (Project No. HKU7166/08E) and The University of Hong Kong through Small Project Funding 20102011. 


\section{References}

Adam, J.M., Ivorra, S., Gimenez E, Moragues, J.J., Miguel, P., Miragall, C., and Calderon, P.A., 2007. Behaviour of axially loaded RC columns strengthened by steel angles and strips. Steel and Composite Structures, 7(5), 405-419.

Adam, J.M., Ivorra, S., Pallares, F.J., Gimenez, E., and Calderon, P.A., 2009a. Axially loaded RC columns strengthened by steel caging: Finite element modeling. Construction and Building Materials, 23(6), 2265-2276.

Adam, J.M., Ivorra, S., Pallares, F.J., Gimenez, E., and Calderon, P.A., 2009b. Axially loaded RC columns strengthened by steel caging. Proc. ICE - Structures and Buildings, 162(3), 199-208.

Calderón, P.A., Adam, J.M., Ivorra, S., Pallarés, F.J., and Giménez, E., 2009. Design strength of axially loaded RC columns strengthened by steel caging. Materials and Design, 30(10), 4069-4080.

Cirtek, L., 2001a. RC columns strengthened with bandage - experimental programme and design recommendations. Construction and Building Materials, 15(8), 341-349.

Cirtek, L., 2001b. Mathematical model of RC banded column behaviour. Construction and Building Materials, 15(8), 351-359.

Collins, M. P., and Mitchell, D., 1987. Prestressed concrete structures. Prentice Hall, Englewood Cliffs, NJ.

De Luca, A., Nardone, F., Matta, F., Nanni, A., Liqnola, G., and Prota, A., 2011. Structural evaluation of full-scale FRP-confined reinforced concrete columns. Journal of Composites for Construction, $15(1), 112-123$.

EC2. Eurocode2: Design of concrete structures-Part 1-1: General rules and rules for buildings. London, UK, British Standards Institution; 2004. BS EN1992-1-1.

El Maaddawy, T., 2008a. Behavior of corrosion-damaged RC columns wrapped with FRP under combined flexural and axial loading. Cement and Concrete Composites, 30, 524-34. 
El Maaddawy, T., 2008b. Post-repair performance of eccentrically loaded RC columns wrapped with CFRP composites. Cement and Concrete Composites, 30, 822-30.

El Maaddawy, T., 2009. Strengthening of eccentrically loaded reinforced concrete columns with fiberreinforced polymer wrapping system: experimental investigation and analytical modeling. Journal of Composites for Construction, 13, 13-24.

Ersoy, U., Suleiman, R., and Tankut, T., 1993. Behavior of jacketed columns. ACI Structural Journal, 90(3), 288-293.

Frangou, M., Pilakoutas, K., and Dritsos, S., 1995. Structural repair/strengthening of RC columns. Construction and Building Materials, 9(5), 259-266.

Garzón-Roca, J., Adam, J.M., and Calderón, P.A., 2011a. Behaviour of RC columns strengthened by steel caging under combined bending and axial loads. Construction and Building Materials, 25(5), 2402-2412.

Garzón-Roca, J., Ruiz-Pinilla, J., Adam, J.M., and Calderón, P.A., 2011b. An experimental study on steel-caged RC columns subjected to axial force and bending moment. Engineering Structures, 33(2), 580-590.

Gere, J.M., and Timoshenko, S., 1990. Mechanics of materials. 3th Edition. Pws-Kent Pub. Co.

Giménez, E., Adam, J.M., Ivorra, S., and Calderón, P.A., 2009a. Influence of strips configuration on the behaviour of axially loaded RC columns strengthened by steel caging and strips. Materials and Design, 30(10), 4103-4111.

Giménez, E., Adam, J.M., Ivorra, S., Moragues, J.J., and Calderón, P.A., 2009b. Full-scale testing of axially loaded RC columns strengthened by steel angles and strips. Advances in Structural Engineering, 12(2), 169-181.

Hadi, M.N.S., and Li, J., 2004. External reinforcement of high strength concrete columns. Composite Structures, 65, 279-287. 
Hadi, M.N.S., 2006a. Behaviour of FRP wrapped normal strength concrete columns under eccentric loading. Composite Structures, 72, 503-511.

Hadi, M.N.S., 2006b. Comparative study of eccentrically loaded FRP wrapped columns. Composite Structures, 74, 127-135.

Hadi, M.N.S., 2007a. Behaviour of FRP strengthened concrete columns under eccentric compression loading. Composite Structures, 77, 92-96.

Hadi, M.N.S., 2007b. The behaviour of FRP wrapped HSC columns under different eccentric loads. Composite Structures, 78, 560-566.

Hadi, M.N.S., 2009. Behaviour of eccentric loading of FRP confined fibre steel reinforced concrete columns. Construction and Building Materials, 23, 1102-1108.

Hognestad, E., Hanson, N., and McHenry, D., 1955. Concrete stress distribution in ultimate strength design. ACI Structural Journal, 52(6), 455-479.

Hu, B., Wang, J.G., and Li, G.Q., 2011. Numerical simulation and strength models of FRP wrapped reinforced concrete columns under eccentric loading. Construction and Building Materials, 25, 27512763.

Jiang, T., and Teng, J.G., 2007. Analysis-oriented stress-strain models for FRP-confined concrete. Engineering Structures, 29, 2968-86.

Lam, L., and Teng, J.G., 2003a. Design-oriented stress-strain model for FRP-confined concrete. Construction and Building Materials, 17,471-89.

Lam, L., and Teng, J.G., 2003b. Design-oriented stress-strain model for FRP-confined concrete in rectangular columns. Journal of Reinforced Plastic and Composites, 22, 1149-86.

Li, J., Gong, J., and Wang, L., 2009. Seismic behavior of corrosion-damaged reinforced concrete columns strengthened using combined carbon fiber-reinforced polymer and steel jacket. Construction and Building Materials, 23(7), 2653-2663. 
Montuori, R., and Piluso, V., 2009. Reinforced concrete columns strengthened with angles and battens subjected to eccentric load. Engineering Structures, 31(2), 539-550.

Park, R., and Paulay, T., 1975. Reinforced concrete structures. John Wiley \& Sons publications.

Pellegrino, C., and Modena, C., 2010. Analytical model for FRP confinement of concrete columns with and without internal steel reinforcement. Journal of Composites for Construction, 14(6), $693-705$.

Quiertant, M., and Clement, J.L., 2011. Behavior of RC columns strengthened with different CFRP systems under eccentric loading. Construction and Building Materials, 25, 452-460.

Ramirez, J.L., 1996. Ten concrete column repair methods. Construction and Building Materials, 10(3), 195-202.

Sadeghian, P., Rahai, A.R., and Ehsani, M.R., 2010. Experimental study of rectangular RC columns strengthened with CFRP composites under eccentric loading. Journal of Composites for Construction, 14, 443-150.

Song, X., Gu, X., Li,Y., Chen, T., and Zhang, W., 2013. Mechanical behavior of FRP-strengthened concrete columns subjected to concentric and eccentric compression loading. Journal of Composites for Construction, 17(3), 336-346.

Su, R.K.L., and Wang, L., 2012. Axial strengthening of preloaded rectangular concrete columns by precambered steel plates. Engineering Structures, 38(5), 42-52.

Su, R.K.L., Siu, W.H., and Smith, S.T., 2010. Effects of bolt-plate arrangements on steel plate strengthened reinforced concrete beams. Engineering Structures, 32(6), 1769-1778.

Takeuti, R.A., de Hanai, J.B., and Mirmiran, A., 2008. Preloaded RC columns strengthened with highstrength concrete jackets under uniaxial compression. Materials and Structures, 41(7), 1251-1262.

Teng, J.G., Chen, J.F., Smith, S.T., and Lam, L., 2003. Behaviour and strength of FRP-strengthened RC structures: a state-of-the-art review. Proc. ICE - Structure and Buildings, 156(1), 51-62.

Teng, J.G., Jiang, T., Lam, L., and Luo, Y.Z., 2009. Refinement of a design-oriented stress-strain 
model for FRP-confined concrete. Journal of Composites for Construction, 13, 269-78.

Timoshenko, S.P., and Gere, J.M., 1961. Theory of elastic stability. Mcgraw-Hill.

Wang, L., and Su, R.K.L., 2012. Experimental investigation of preloaded RC columns strengthened with precambered steel plates under eccentric compression loading. Advances in Structural Engineering, 15(8), 1253-1264.

Wang, L., and Su, R.K.L., 2013a. Theoretical and experimental study of plate-strengthened concrete columns under eccentric compression loading. Journal of Structural Engineering, ASCE, 139(3), 350-359.

Wang, L., and Su, R.K.L., 2013b. Axial Behaviour of Post-Fire RC Columns Strengthened with PostCompressed Steel Plates. International Conference on Design, Fabrication and Economy of Metal Structures, 413-419, Miskolc, Hungary.

Wang, L., and Su, R.K.L., 2014. Repair of fire-exposed preloaded rectangular concrete columns by postcompressed steel plates. Journal of Structural Engineering, ASCE, (in press) DOI: 10.1061/(ASCE)ST.1943-541X.0000884.

Wei, Y.Y., and Wu, Y.F., 2012. Unified stress-strain model of concrete for FRP-confined columns. Construction and Building Materials. 26, 381-392.

Wu, Y.F., Liu, T., and Oehlers, D.J., 2006. Fundamental principles that govern retrofitting of reinforced concrete columns by steel and FRP jacketing. Advances in Structural Engineering, 9(4), $507-533$.

Wu, Y.F., and Jiang, C., 2013. Effect of load eccentricity on the stress-strain relationship of FRPconfined concrete columns. Composite structures, 98, 228-241.

Yang, K.H., and Ashour, A.F., 2007. Tests of reinforced concrete short columns laterally strengthened with wire rope units and steel elements. Magazine of concrete research, 59(8), 547-557.

Yang, K.H., Ashour, A.F., and Lee, E.T., 2009. Axial behaviour of reinforced concrete short columns strengthened with wire rope and T-shaped steel plate units. Magazine of concrete research, 61(2), $143-154$. 
Nomenclature

$A_{p c} \quad$ cross-sectional area of the precambered steel plate

$A_{p t} \quad$ cross-sectional area of the flattened steel plate

$A_{s c}$ total cross-sectional areas of the compression steel bars

$A_{s t}$ total cross-sectional areas of the tension steel bars

$b$ width of the column section depth of the compression zone in the preloading stage

$c_{u} \quad$ depth of the compression zone

$d \quad$ depth of the tension steel bars measured from the extreme compression fibre.

$d$ depth of the compression steel bars measured from the extreme compression fibre

$e \quad$ degree of eccentricity

$e^{\prime} \quad$ distance between the loading point and the tension steel bars

$E_{p} \quad$ Young's modulus of the steel plates

$E_{p c} \quad$ Young's modulus of the precambered steel plate

$E_{s} \quad$ Young's modulus of the steel bars

$f_{c u}$

$f_{c}^{\prime}$ compressive cube strength of the concrete compressive cylinder strength of the concrete;

$f_{s c y} \quad$ yield strength of compression steel bars

$f_{p t} \quad$ stress in the tension steel plate

$f_{s t} \quad$ stress in the tension steel bar

$h \quad$ depth of the RC column

$L_{n a} \quad$ height of the RC column at the neutral axis position.

$L_{r c} \quad$ clear height of the RC column

$L_{r c, p l} \quad$ clear height of the RC column under preloading

$L_{r c, p s} \quad$ height of the RC column at the compression side after the flattening of the plate

$M_{p} \quad$ primary moment calculated based on the nominal eccentricity;

$M_{s} \quad$ secondary moment due to $P$ - $\Delta$ effect

$M_{u} \quad$ ultimate moment at the mid-height of the column

$P_{\text {exp }} \quad$ experimental ultimate load capacity

$P_{\text {Mon,exp }} \quad$ test result from Montuori and Piluso (2009)

$P_{\text {Mon,pre }} \quad$ predicted result from Montuori and Piluso (2009)

$P_{p c, p s} \quad$ post-compressive force

$P_{p l} \quad$ preloading level

$P_{\text {pre }} \quad$ predicted ultimate load capacity

$P_{p, c r} \quad$ critical load of the steel plate

$R_{p l} \quad$ radius of curvature of the RC column under the preloading

$R_{p s} \quad$ radius of curvature of the RC column after the flattening of the plate

$s_{\max } \quad$ maximum bolt spacing

$t_{p c} \quad$ thickness of compression plate

$t_{p t} \quad$ thickness of tension plate

$x \quad$ coordinate defined along the height of the column

$\alpha \quad$ stress block factors of concrete stress distribution

$\beta \quad$ stress block factors of concrete stress distribution

$\delta \quad$ nitial precamber

$\varepsilon_{c} \quad$ strain of the concrete

$\varepsilon_{c 0} \quad$ concrete compressive strain corresponding to $f_{c}$ 


\begin{tabular}{|c|c|}
\hline$\varepsilon_{c u}$ & ultimate concrete compressive strain \\
\hline$\varepsilon_{c, p l}$ & concrete strain at the extreme compression fibres in the preloading stage \\
\hline$\varepsilon_{c, p s}$ & strain of the concrete in the post-stressing stage \\
\hline$\varepsilon_{c, p s}$ & strain of the concrete in the post-stressing stage iii \\
\hline$\varepsilon_{c, p s}^{\mathrm{v}}$ & strain of the concrete in the post-stressing stage $\mathrm{v}$ \\
\hline$\varepsilon_{p}$ & strain of the steel plates \\
\hline$\varepsilon_{p c}$ & strain of precambered steel plate \\
\hline$\varepsilon_{p c, p s}$ & plate compressive strain in the post-stressing stage \\
\hline$\varepsilon^{111} p c, p s$ & plate compressive strain in the post-stressing stage iii \\
\hline$\varepsilon_{p c, p s}^{\mathrm{v}}$ & plate compressive strain in the post-stressing stage $\mathrm{v}$ \\
\hline$\varepsilon_{p, p e a k}$ & maximum strain of steel plate under peak loading \\
\hline$\varepsilon_{s}$ & strain of the steel bars \\
\hline$\varepsilon_{s c, p l}$ & steel bar compressive strain in the preloading stage \\
\hline$\varepsilon_{s c, p s}$ & steel bar compressive strain in the post-stressing stage \\
\hline$\varepsilon^{\mathrm{iii}}{ }_{s c, p s}$ & steel bar compressive strain in the post-stressing stage iii \\
\hline$\varepsilon_{s c, p s}^{\mathrm{v}}$ & steel bar compressive strain in the post-stressing stage $\mathrm{v}$ \\
\hline$\varepsilon_{s t, p l}$ & steel bar tensive strain in the preloading stage \\
\hline$\varepsilon_{s t, p s}$ & steel bar tensive strain in the post-stressing stage \\
\hline$\varepsilon^{\mathrm{iii}^{\mathrm{t}}}{ }_{s c, p s}$ & steel bar tensive strain in the post-stressing stage iii \\
\hline$\varepsilon_{s c, p s}^{\mathrm{v}}$ & steel bar tensive strain in the post-stressing stage $\mathrm{v}$ \\
\hline$\zeta_{u}$ & mid-span horizontal deflection \\
\hline$\eta$ & displacement ductility factor \\
\hline$\lambda$ & deformability factor \\
\hline$\mu$ & factor related to the boundary conditions for the columns \\
\hline$\sigma_{c}$ & stress of the concrete \\
\hline$\sigma_{p}$ & stress of the steel plates \\
\hline$\sigma_{s}$ & stress of the steel bars \\
\hline$\varphi_{p l}$ & curvature of the $\mathrm{RC}$ column under the preloading \\
\hline$\varphi_{p s}$ & curvature of the RC column when the precambered steel plate is flattened \\
\hline$\Delta_{f}$ & axial shortening at the failure load; \\
\hline$\Delta_{L}$ & difference in the length of the steel plate and the RC column \\
\hline$\Delta_{p c, p s}$ & plate axial shortening in the post-stressing stage \\
\hline$\Delta_{p c, p s}$ & plate axial shortening in the post-stressing stage \\
\hline$\Delta_{u}$ & axial shortening at the ultimate load \\
\hline$\Delta y$ & axial shortening at the yield load \\
\hline
\end{tabular}


Table 1. Summary of strengthening details

\begin{tabular}{cccccccccc}
\hline Group & Specimen & $\begin{array}{c}f_{c u} \\
(\mathrm{MPa})\end{array}$ & $\begin{array}{c}f^{\prime}{ }_{c} \\
(\mathrm{MPa})\end{array}$ & $\begin{array}{c}L_{r c} \\
(\mathrm{~mm})\end{array}$ & $\begin{array}{c}e \\
(\mathrm{~mm})\end{array}$ & $\begin{array}{c}t_{p t} \\
(\mathrm{~mm})\end{array}$ & $\begin{array}{c}t_{p c} \\
(\mathrm{~mm})\end{array}$ & $\begin{array}{c}\delta \\
(\mathrm{mm})\end{array}$ & $\begin{array}{c}P_{p l} \\
(\mathrm{kN})\end{array}$ \\
\hline A & MSC1-1 & 32.7 & 26.6 & 600 & 60 & - & - & - & - \\
& MSC1-2 & 32.9 & 25.0 & 600 & 60 & 6 & 6 & 10 & 65 \\
& MSC1-3 & 32.6 & 26.2 & 600 & 60 & 3 & 6 & 10 & 65 \\
& & & & & & & & & \\
B & MSC2-1 & 29.7 & 24.2 & 600 & 100 & - & - & - & - \\
& MSC2-2 & 29.5 & 24.4 & 600 & 100 & 3 & 3 & 10 & 43 \\
& MSC2-3 & 29.5 & 24.4 & 600 & 100 & 6 & 6 & 6 & 43 \\
& MSC2-4 & 30.1 & 24.7 & 600 & 100 & 6 & 6 & 10 & 43 \\
& MSC2-5 & 31.6 & 25.2 & 600 & 100 & 3 & 6 & 10 & 43 \\
& & & & & & & & & \\
C & MSC3-1 & 32.7 & 26.6 & 600 & 140 & - & - & - & - \\
& MSC3-2 & 31.6 & 25.2 & 600 & 140 & 6 & 6 & 10 & 29 \\
\hline
\end{tabular}

Table 2. Material properties of reinforcements and steel plates

\begin{tabular}{ccc}
\hline \multicolumn{3}{c}{ Steel Plates } \\
\hline $\begin{array}{c}\text { Thickness } \\
(\mathrm{mm})\end{array}$ & $\begin{array}{c}\text { Yield strength } \\
(\mathrm{MPa})\end{array}$ & $\begin{array}{c}\text { Young's modulus } \\
(\mathrm{GPa})\end{array}$ \\
\hline 3 & 321 & 197 \\
6 & 329 & 202 \\
\hline
\end{tabular}

\begin{tabular}{ccc}
\hline \multicolumn{3}{c}{ Reinforcement bars } \\
\hline Bar type & $\begin{array}{c}\text { Yield strength } \\
(\mathrm{MPa})\end{array}$ & $\begin{array}{c}\text { Young's modulus } \\
(\mathrm{GPa})\end{array}$ \\
\hline T10 & 495 & 197 \\
T12 & 516 & 198 \\
R6 & 464 & 186 \\
R8 & 437 & 187 \\
\hline
\end{tabular}


Table 3. Summary of strengthening results

\begin{tabular}{ccccccccccc}
\hline Group & Specimen & $\begin{array}{c}\zeta_{u} \\
(\mathrm{~mm})\end{array}$ & $\begin{array}{c}M_{p} \\
(\mathrm{kNm})\end{array}$ & $\begin{array}{c}M_{s} \\
(\mathrm{kNm})\end{array}$ & $\begin{array}{c}M_{u} \\
(\mathrm{kNm})\end{array}$ & $\begin{array}{c}P_{\text {exp }} \\
(\mathrm{kN})\end{array}$ & $\begin{array}{c}P_{\text {pre }} \\
(\mathrm{kN})\end{array}$ & $P_{\text {pre }} / P_{\text {exp }}$ & $\varepsilon_{p, p e a k}$ & Failure mode \\
\hline A & MSC1-1 & 9.45 & 13.08 & 2.06 & 15.14 & 218 & 213 & 0.98 & - & Compression \\
& MSC1-2 & 8.37 & 23.34 & 3.26 & 26.60 & 389 & 381 & 0.98 & 0.00141 & Compression \\
& MSC1-3 & 8.88 & 21.60 & 3.20 & 24.80 & 360 & 368 & 1.02 & 0.00132 & Compression \\
& & & & & & & & & & \\
B & MSC2-1 & 10.11 & 14.30 & 1.45 & 15.73 & 143 & 143 & 1.00 & - & Tension \\
& MSC2-2 & 12.03 & 23.80 & 2.86 & 26.66 & 238 & 218 & 0.92 & 0.00152 & Tension \\
& MSC2-3 & 15.69 & 29.50 & 4.92 & 34.42 & 295 & 298 & 1.01 & 0.00137 & Tension \\
& MSC2-4 & 14.67 & 33.30 & 4.89 & 38.19 & 333 & 303 & 0.91 & 0.00138 & Tension \\
& MSC2-5 & 13.93 & 27.00 & 3.76 & 30.76 & 275 & 272 & 0.99 & 0.00133 & Tension \\
& & & & & & & & & & \\
C & MSC3-1 & 9.83 & 13.72 & 0.96 & 14.68 & 89 & 97 & 1.09 & - & Tension \\
& MSC3-2 & 17.14 & 33.46 & 4.10 & 37.56 & 234 & 223 & 0.95 & 0.00140 & Tension \\
\hline Mean & - & - & - & - & - & - & - & 0.99 & - & - \\
St. DEV & - & - & - & - & - & - & - & 0.05 & - & - \\
\hline
\end{tabular}

Table 4. Summary of deformability and ductility factors

\begin{tabular}{ccccccc}
\hline Group & Specimen & $\begin{array}{c}\Delta_{y} \\
(\mathrm{~mm})\end{array}$ & $\begin{array}{c}\Delta_{u} \\
(\mathrm{~mm})\end{array}$ & $\begin{array}{c}\Delta_{f} \\
(\mathrm{~mm})\end{array}$ & $\lambda$ & $\eta$ \\
\hline $\mathrm{A}$ & MSC1-1 & 0.35 & 0.56 & 0.71 & 1.27 & 1.60 \\
& MSC1-2 & 0.89 & 1.77 & 2.33 & 1.32 & 1.99 \\
& MSC1-3 & 1.01 & 1.73 & 2.57 & 1.49 & 1.71 \\
& & & & & & \\
$\mathrm{~B}$ & MSC2-1 & 0.14 & 0.21 & 0.27 & 1.29 & 1.50 \\
& MSC2-2 & 1.59 & 2.45 & 3.27 & 1.33 & 1.54 \\
& MSC2-3 & 1.12 & 1.53 & 2.17 & 1.37 & 1.61 \\
& MSC2-4 & 0.93 & 1.61 & 2.85 & 1.77 & 1.73 \\
& MSC2-5 & 1.01 & 1.59 & 2.48 & 1.56 & 1.57 \\
& & & & & & \\
$\mathrm{C}$ & MSC3-1 & 0.14 & 0.19 & 0.21 & 1.11 & 1.36 \\
& MSC3-2 & 0.88 & 1.35 & 1.65 & 1.21 & 1.53 \\
\hline
\end{tabular}


Table 5. Comparison of ultimate load capacities from Montuori and $\underline{\text { Piluso }}$ (2009) and the present proposed Analytical model

\begin{tabular}{cccccc}
\hline Specimen & $\begin{array}{c}P_{\text {Mon,exp }} \\
(\mathrm{kN})\end{array}$ & $\begin{array}{c}P_{\text {Mon,pre }} \\
(\mathrm{kN})\end{array}$ & $\begin{array}{c}P_{\text {pre }} \\
(\mathrm{kN})\end{array}$ & $P_{\text {pre }} / P_{\text {Mon,exp }}$ & $P_{\text {pre }} / P_{\text {Mon, }, \mathrm{pre}}$ \\
\hline A-R1 & 513.95 & 527.02 & 511.82 & 0.99 & 0.97 \\
B-R1a & 703.23 & 683.62 & 681.28 & 0.97 & 0.99 \\
B-R1b & 662.71 & 649.75 & 655.02 & 0.99 & 1.01 \\
C-R1 & 498.74 & 495.15 & 481.39 & 0.97 & 0.97 \\
D-R1 & 545.19 & 553.24 & 515.15 & 0.94 & 0.93 \\
D-R2 & 568.98 & 583.22 & 552.01 & 0.97 & 0.95 \\
D-R3 & 483.63 & 453.84 & 465.61 & 0.96 & 1.03 \\
E-R1 & 713.24 & 713.80 & 697.55 & 0.98 & 0.98 \\
\hline Mean & - & - & - & 0.97 & 0.98 \\
St. DEV & - & - & - & 0.01 & 0.01 \\
\hline
\end{tabular}




\section{List of figures}

Figure 1. The configuration of the column decompression approaches (a) Precambered plates installed on the side faces of RC column and (b) Precambered plate installed on the compression side and flat plate installed on the tension side of RC column.

Figure 2. The details of the column decompression approach (a)before tightening the bolts at the ends of RC column; (b) tightening the bolts at the ends of RC column and (c) description of lateral displacement.

Figure 3. Stress-block factors.

Figure 4. Column curvature profile (a) Preloading stage and (b) Post-stressing stage.

Figure 5. Deformations of RC column under equivalent axial compression loading and bending moment.

Figure 6. Reinforcement and precambered steel plates (a) RC details and (b) Steel plate details.

Figure 7. Test setup (a) schematic diagram and (b) photograph of the test setup.

Figure 8. Instrumentation of MSC2-2.

Figure 9. Post-stressed procedure.

Figure 10. Effects of eccentricity (a) $t_{p c}=0 \mathrm{~mm}, t_{p t}=0 \mathrm{~mm}$ and (b) $t_{p c}=6 \mathrm{~m}, t_{p t}=6 \mathrm{~mm}$.

Figure 11. Effects of plate thickness (a) $e=30 \mathrm{~mm}$ and (b) $e=70 \mathrm{~mm}$.

Figure 12. Effects of initial precamber.

Figure 13. Crack patterns (a) Specimen MSC1-2 and (b) Specimen MSC2-2.

Figure 14. Load-longitudinal strain curves (a) $t_{p t}=0 \mathrm{~mm}, t_{p c}=0 \mathrm{~mm}, \delta=0 \mathrm{~mm}$, (b) $t_{p t}=6 \mathrm{~mm}, t_{p c}=6 \mathrm{~mm}$, $\delta=10 \mathrm{~mm}$, (c) $\delta=10 \mathrm{~mm}, e=100 \mathrm{~mm}$ and (d) $t_{p t}=6 \mathrm{~mm}, t_{p c}=6 \mathrm{~mm}, e=100 \mathrm{~mm}$.

Figure 15. Moment-curvature responses of columns (a) $t_{p c}=6 \mathrm{~mm}, t_{p t}=6 \mathrm{~mm}, \delta=10 \mathrm{~mm}$, (b) $t_{p c}=6 \mathrm{~mm}$, $t_{p t}=6 \mathrm{~mm}, e=100 \mathrm{~mm}$, (c) $e=60 \mathrm{~mm}, \delta=10 \mathrm{~mm}$ and (d) $e=100 \mathrm{~mm}, \delta=10 \mathrm{~mm}$. 


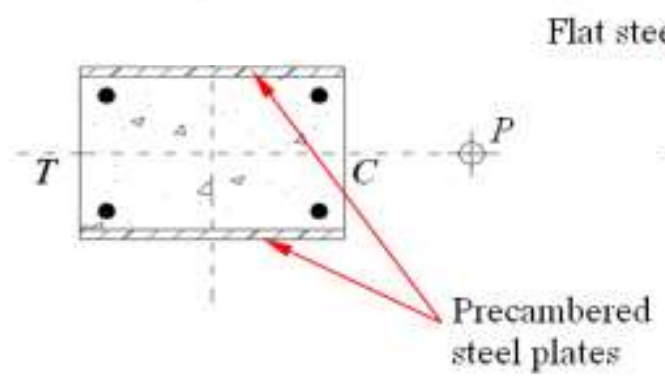

(a)

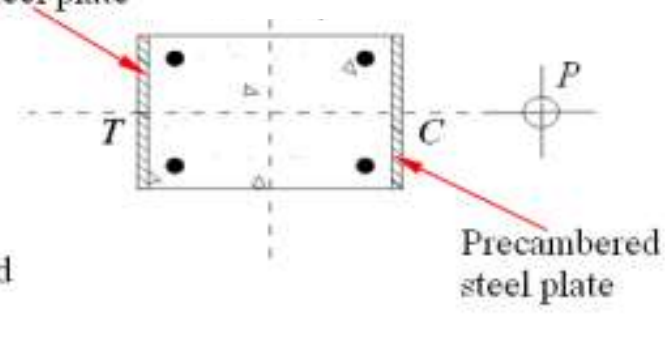

(b)

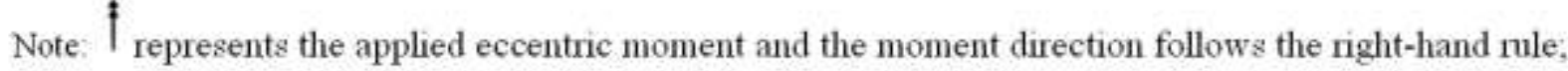 $T$ denotes the tension side, $C$ denotes the compression side.}

Figure 1. The configuration of the column decompression approaches: (a)Precambered plates installed on the side faces of RC column; (b) Precambered plate installed on the compression side and flat plate installed on the tension side of RC column

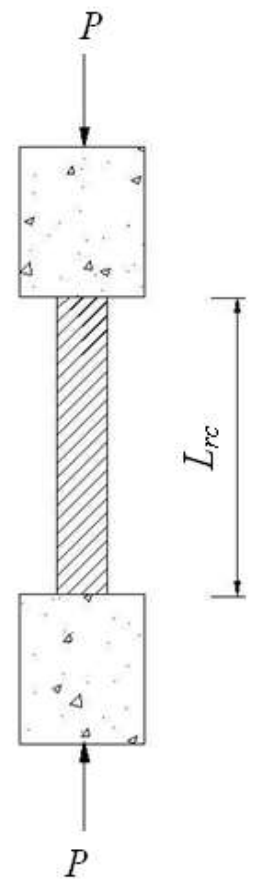

Front view

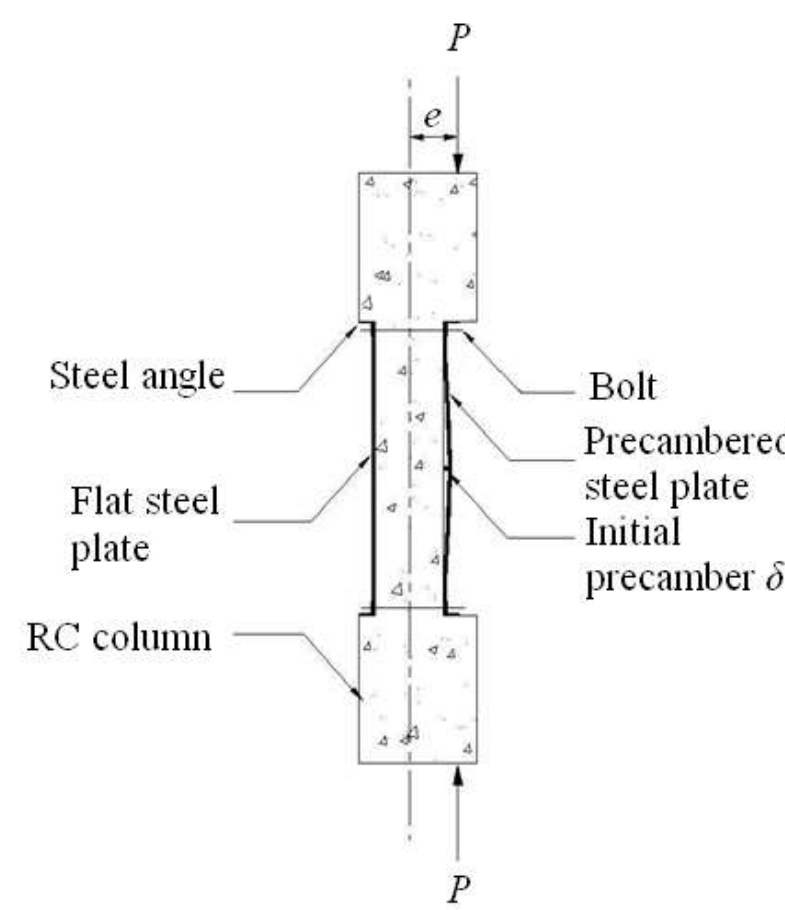

Side view

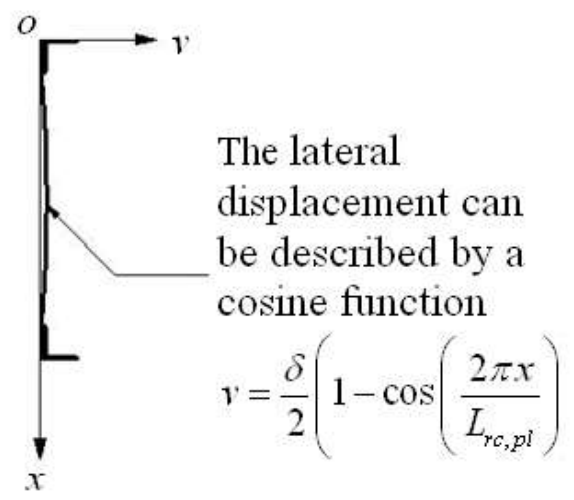

Note: $L_{r c}$ is the clear height of column.

Figure 2. The details of the column decompression approach 


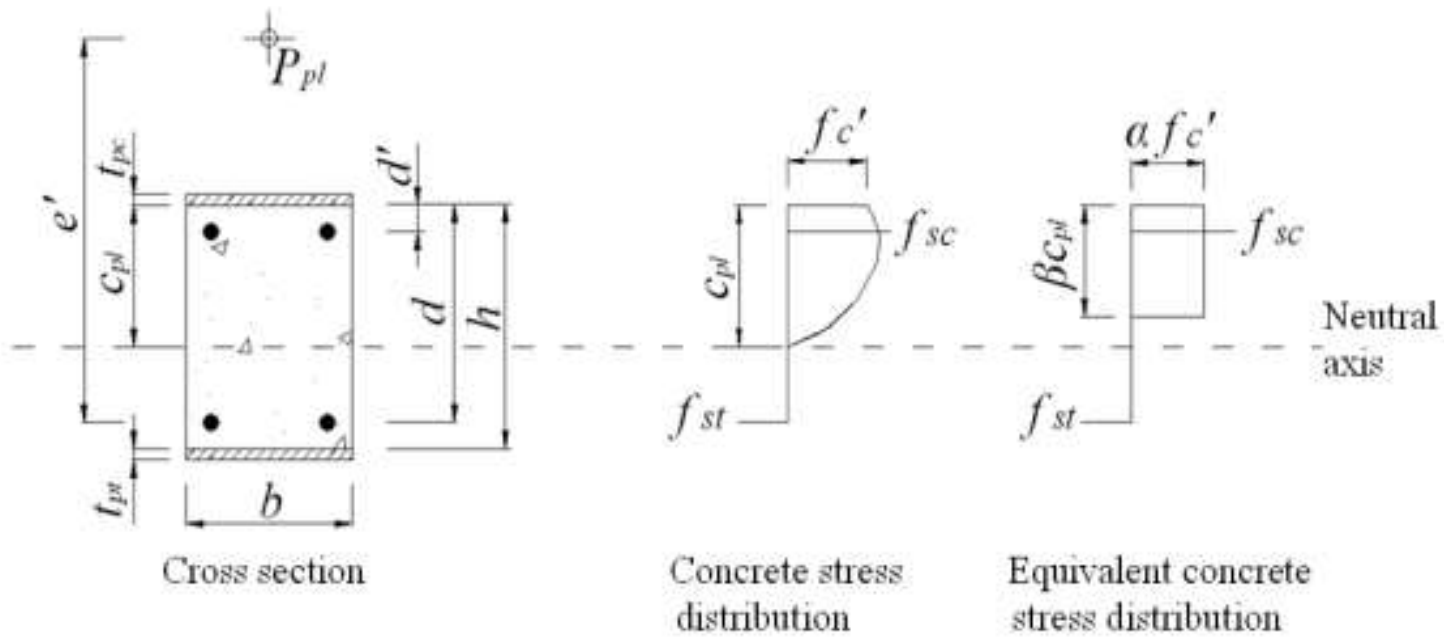

Figure 3. Stress-block factors

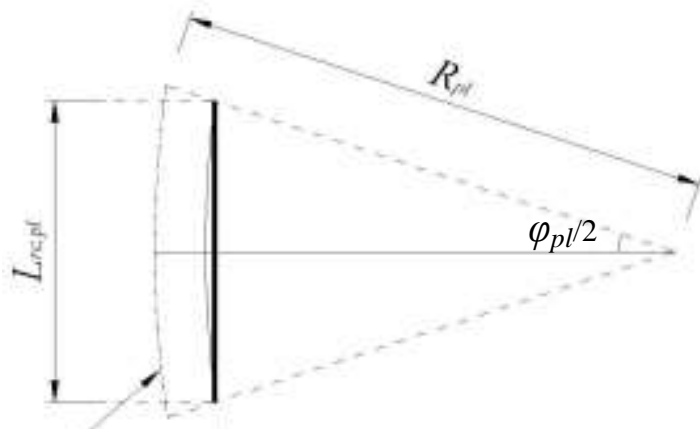

Neutral axis

$$
\text { distribution stress distribution }
$$

(a)

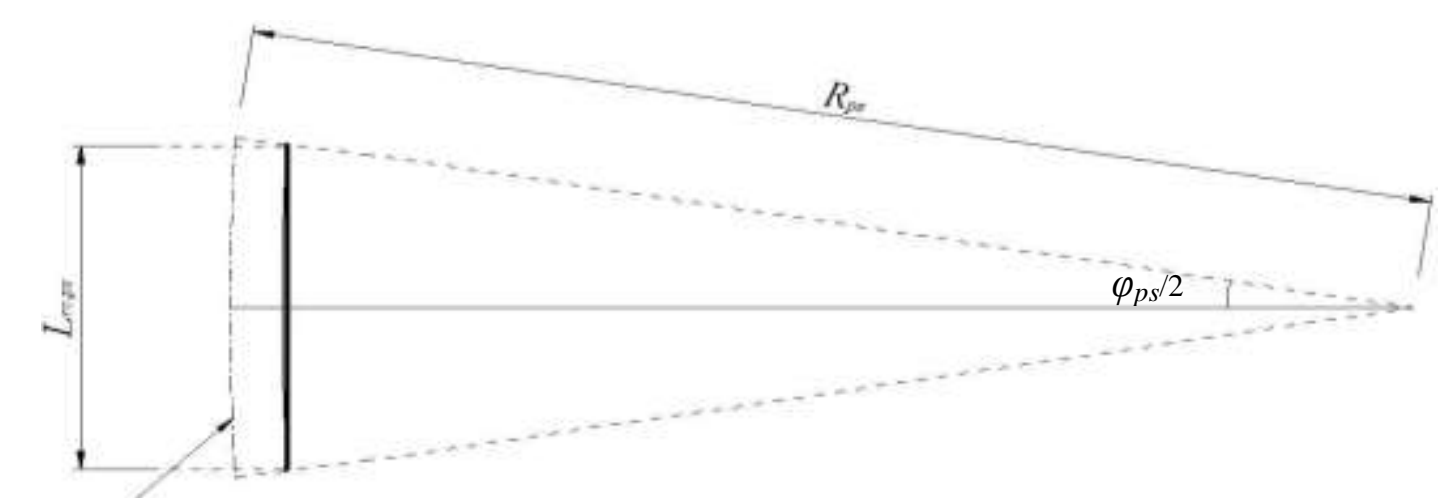

Neutral axis $-\left|c_{p s}\right|$.

(b)

Figure 4. Column curvature profile: (a) Preloading stage; (b) Post-stressing stage 


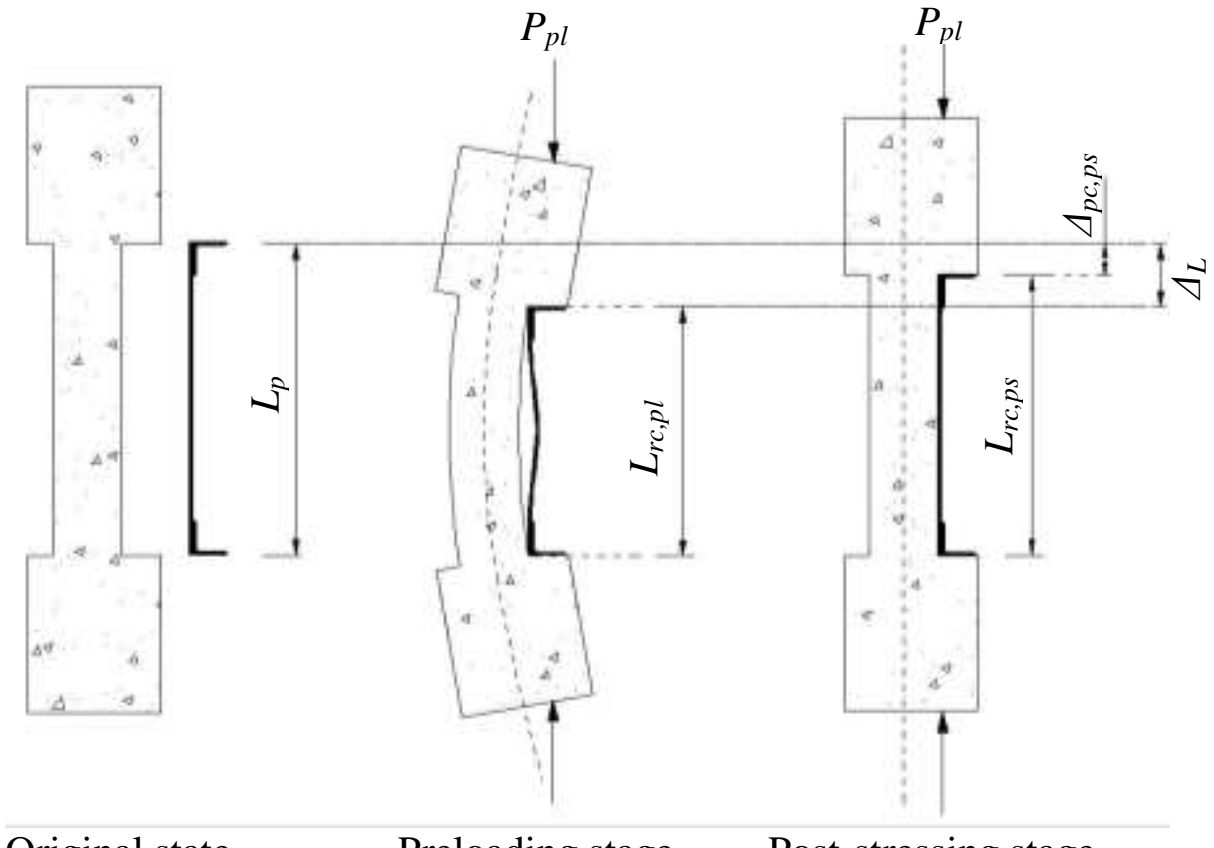

Original state

Preloading stage Post-stressing stage

Figure 5. Deformations of RC column under equivalent axial compression loading and bending moment 


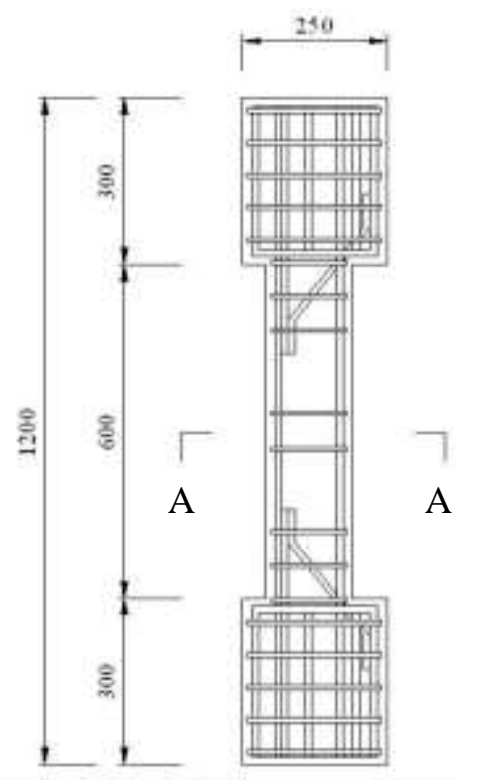

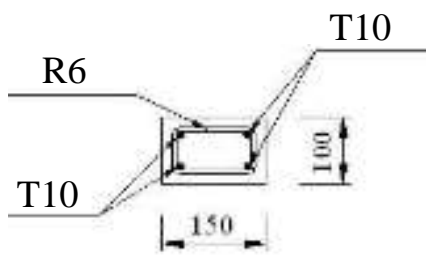

$\underline{A-A}$

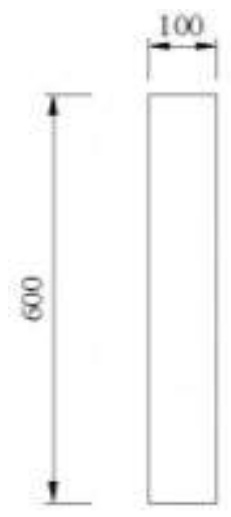

(a)

(b)

Figure 6. Reinforcement and precambered steel plates: (a) RC details; (b) Steel plate details

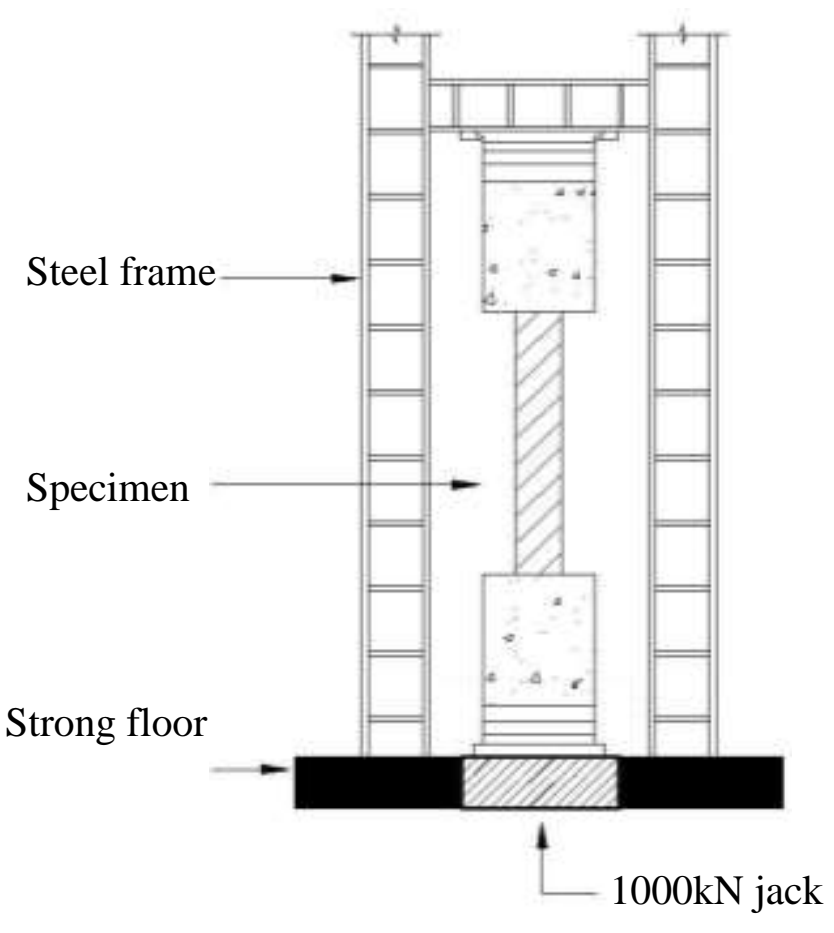

(a)

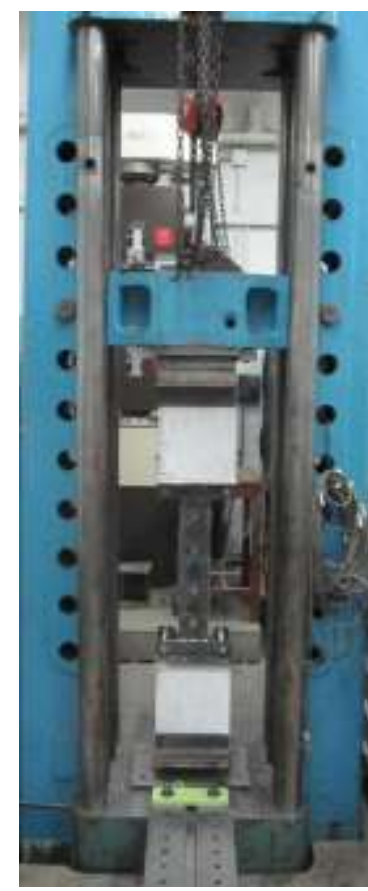

(b)

Figure 7. Test setup: (a) schematic diagram; (b) photograph of the test setup 

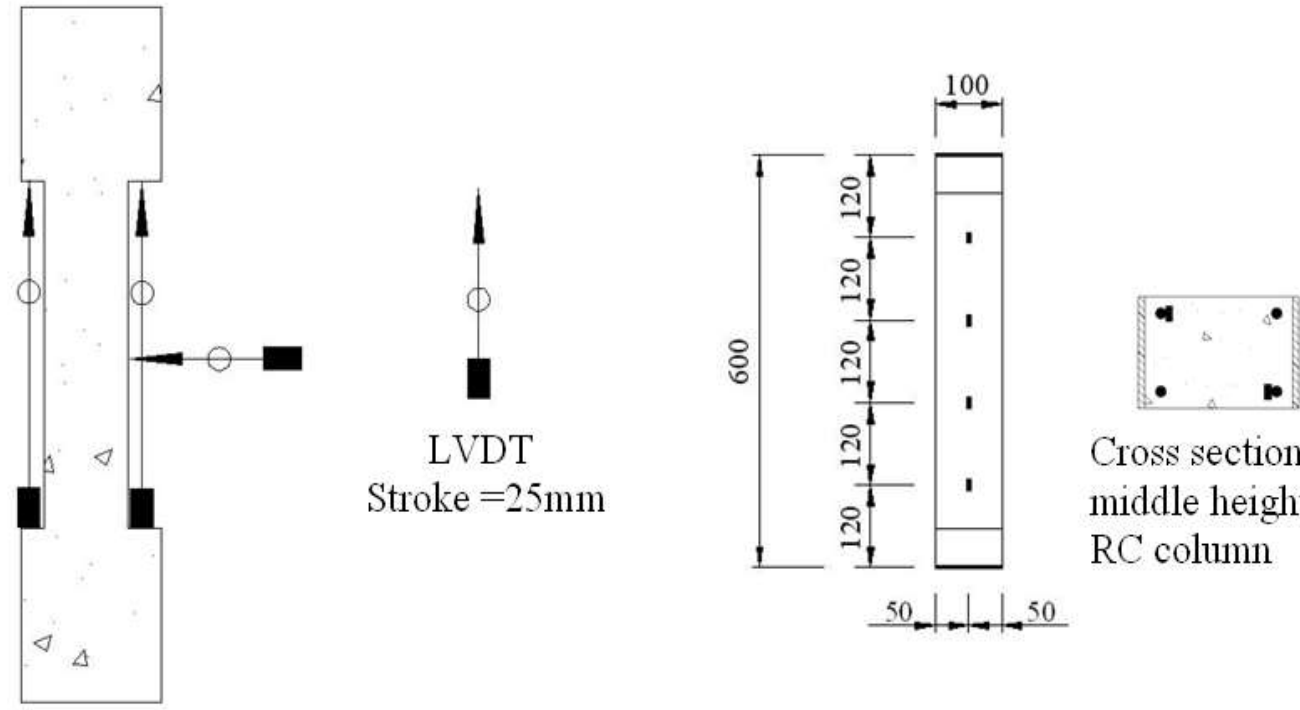

Linear strain

Cross section at middle height of $\mathrm{RC}$ column

Figure 8. Instrumentation of MSC2-2 


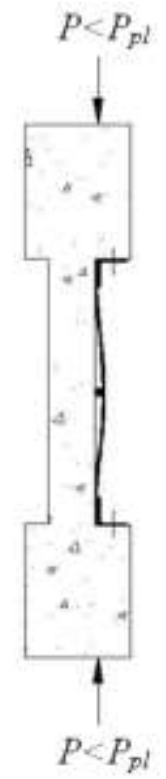

(i) Tightening the upper end bolts, the steel plate hardly provide resistance due to the precamber profile

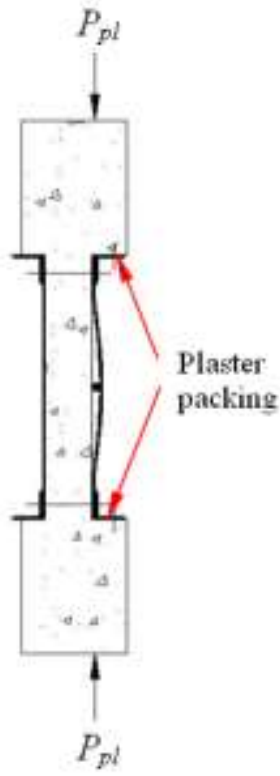

(ii) Adding tension plate and tightening the bottom end bolts; filling the plaster packing mutil reaching the hardening time

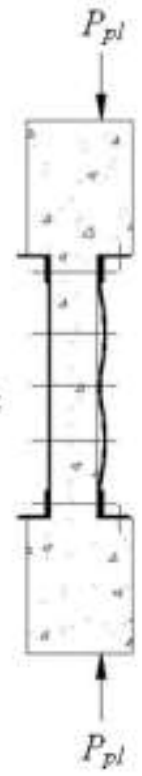

(iii) Tightening the mid-height bolts

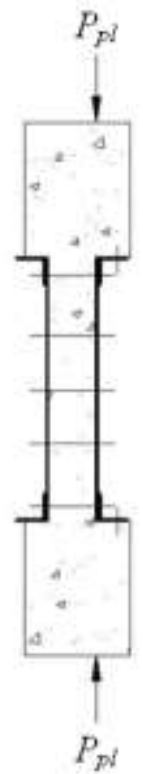

(iv) Flattening the plates

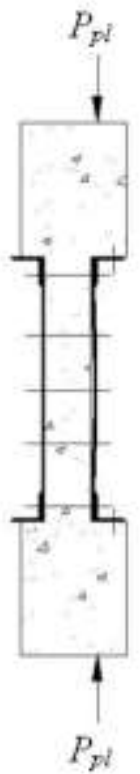

(v) Loosening the bolts

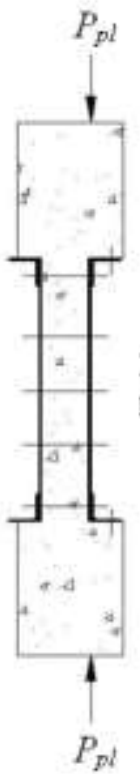

(vi) Fastening the bolts again

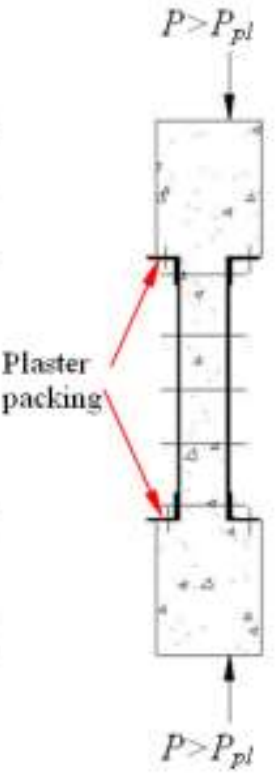

(vii) Fixing the tension plate and filling the plaster packing

(a)
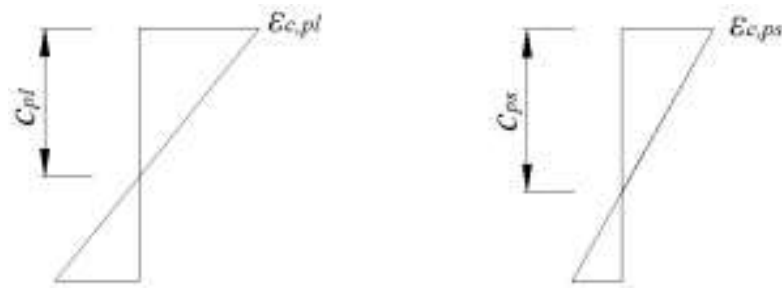

Preloading stage (i \& ii) Post-stressing stage (iii-vii)

(b)

Figure 9. Post-stressed procedure: (a) decompression process; (b) stress distribution in column

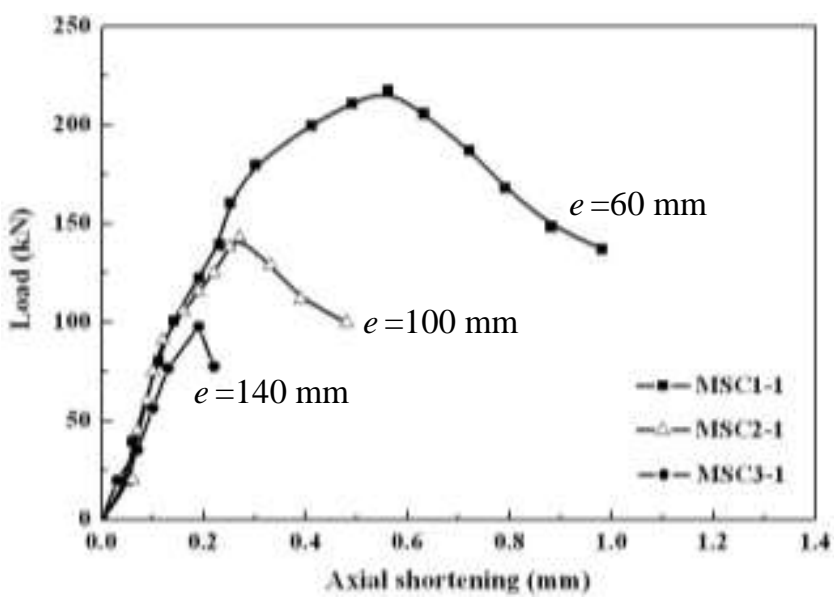

(a)

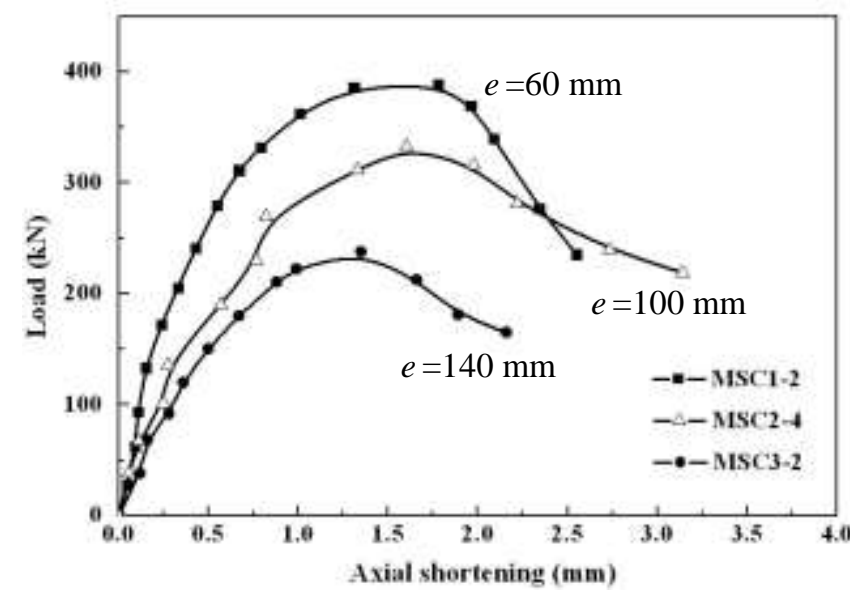

(b)

Figure 10. Effects of eccentricity: (a) $t_{p c}=0 \mathrm{~mm}, t_{p t}=0 \mathrm{~mm}$; (b) $t_{p c}=6 \mathrm{~m}, t_{p t}=6 \mathrm{~mm}$ 


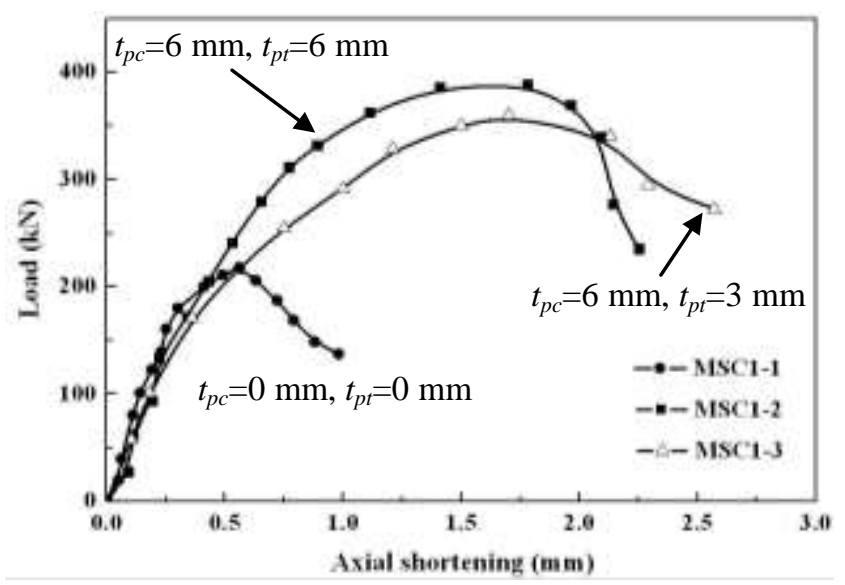

(a)

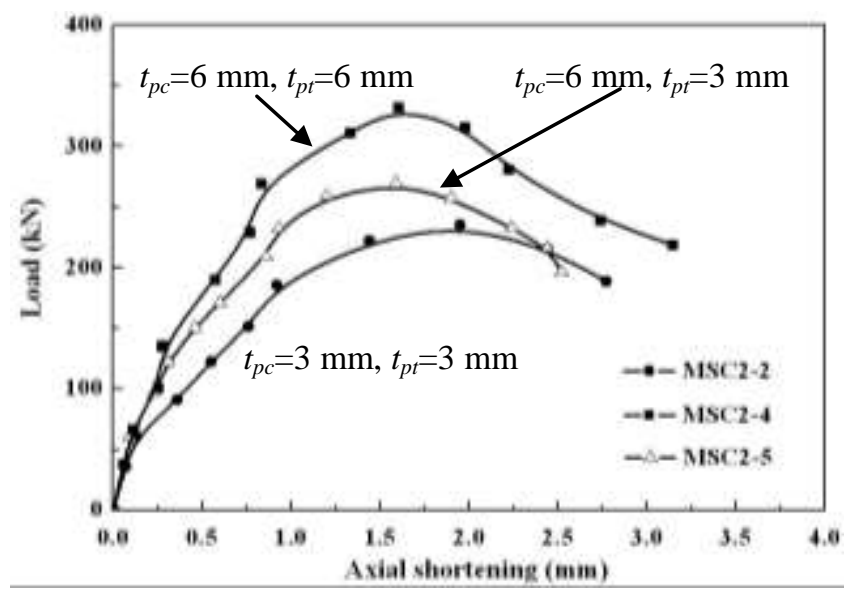

(b)

Figure 11. Effects of plate thickness: (a) $e=30 \mathrm{~mm}$; (b) $e=70 \mathrm{~mm}$

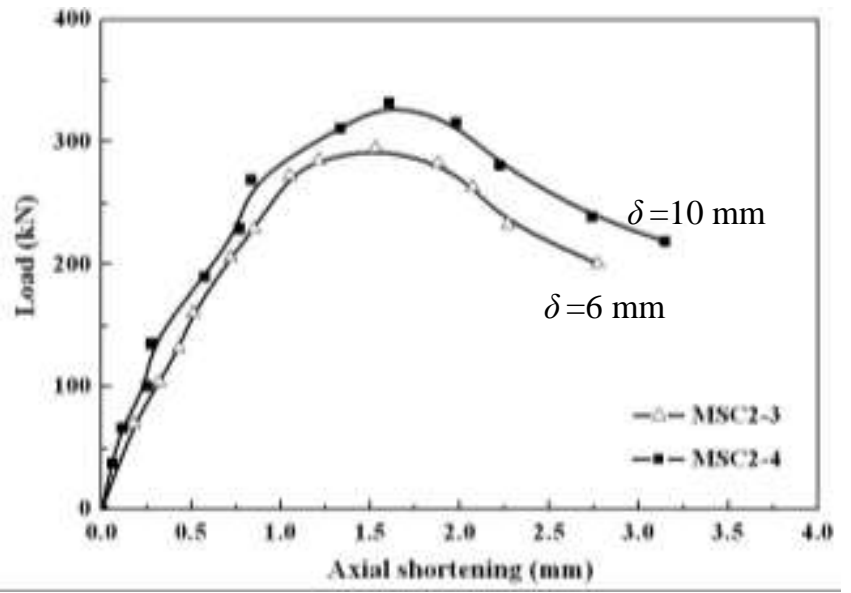

Figure 12. Effects of initial precamber

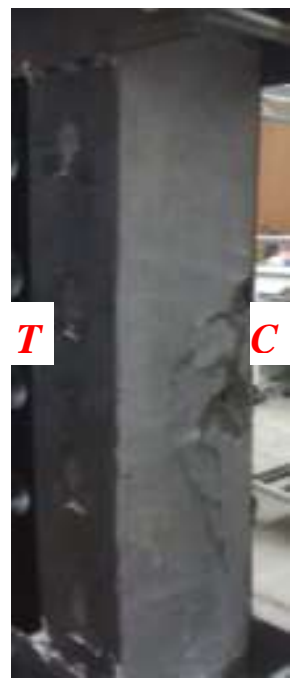

(a)

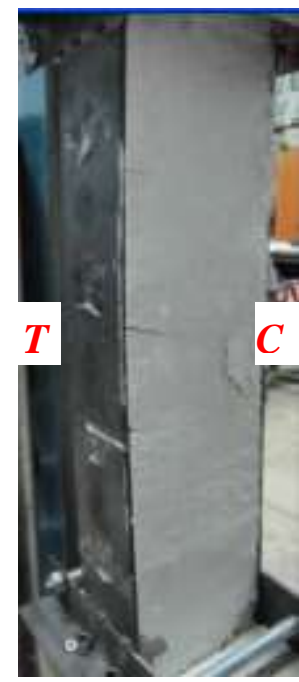

(b)

Note: $\boldsymbol{T}$ denotes the tension side, $\boldsymbol{C}$ denotes the compression side.

Figure 13. Crack patterns: (a) Specimen MSC1-2;(b) Specimen MSC2-2 


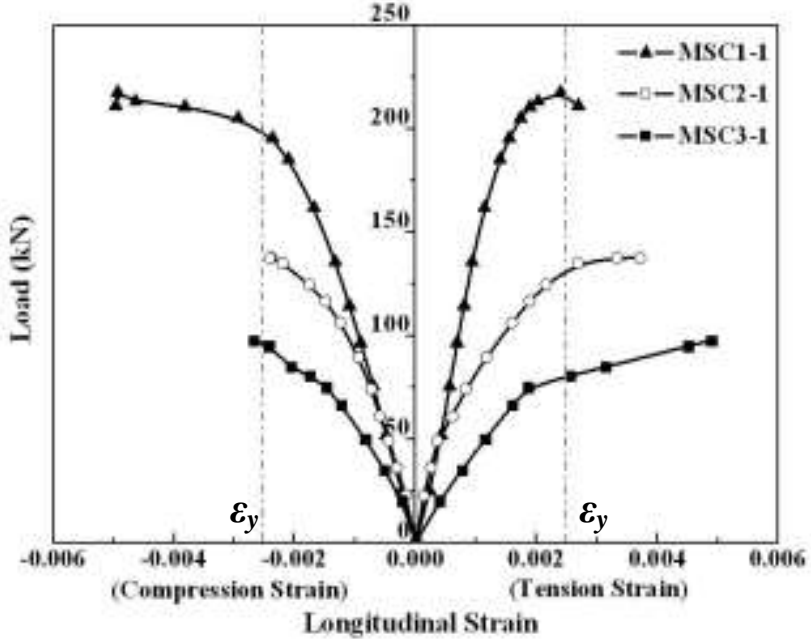

(a)

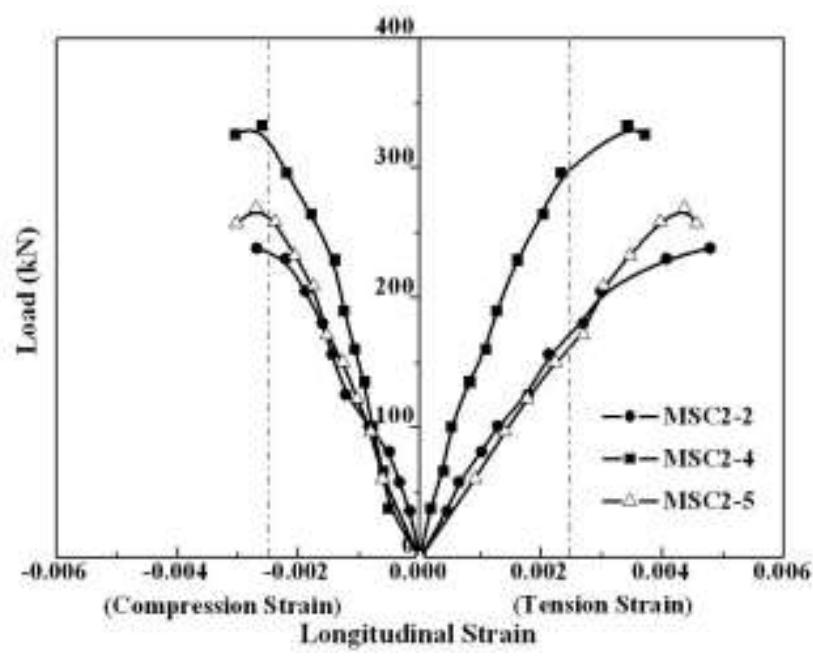

(c)

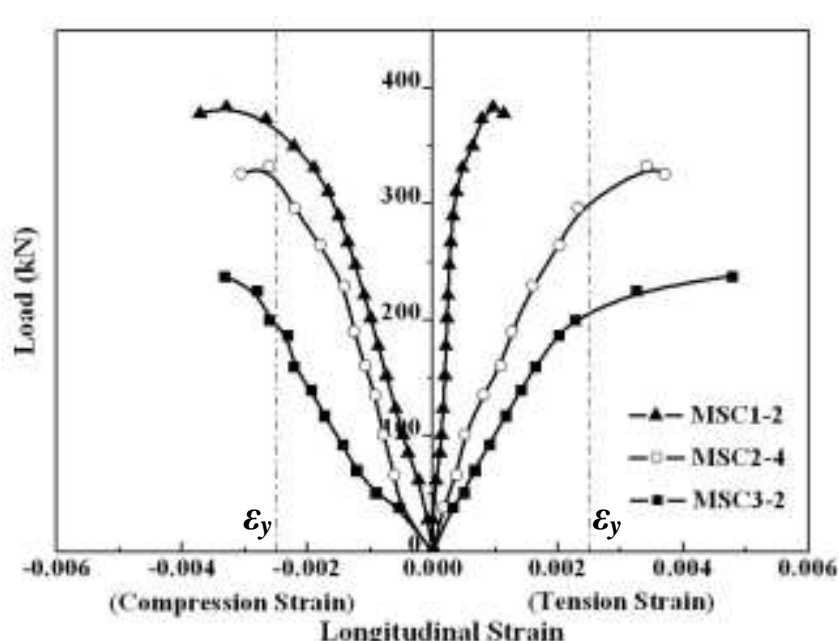

(b)

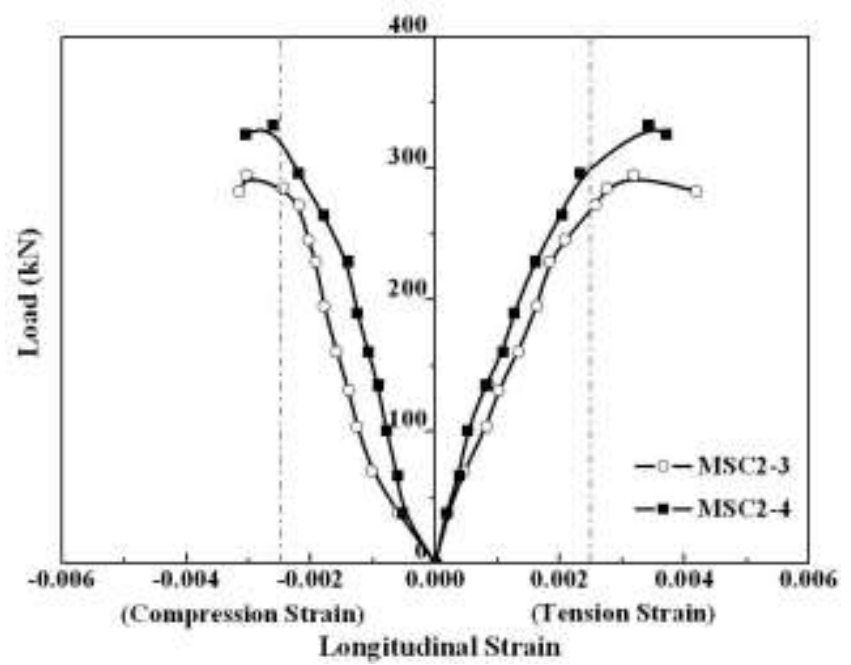

(d)

Note: $\varepsilon_{y}$ is the yield strain of reinforcement, which is equal to 0.0025 .

Figure 14. Load-longitudinal strain curves: (a) $t_{p t}=0 \mathrm{~mm}, t_{p c}=0 \mathrm{~mm}, \delta=0 \mathrm{~mm}$; (b) $t_{p t}=6 \mathrm{~mm}, t_{p c}=6$ $\mathrm{mm}, \delta=10 \mathrm{~mm}$; (c) $\delta=10 \mathrm{~mm}, e=100 \mathrm{~mm} ;(d) t_{p t}=6 \mathrm{~mm}, t_{p c}=6 \mathrm{~mm}, e=100 \mathrm{~mm}$ 


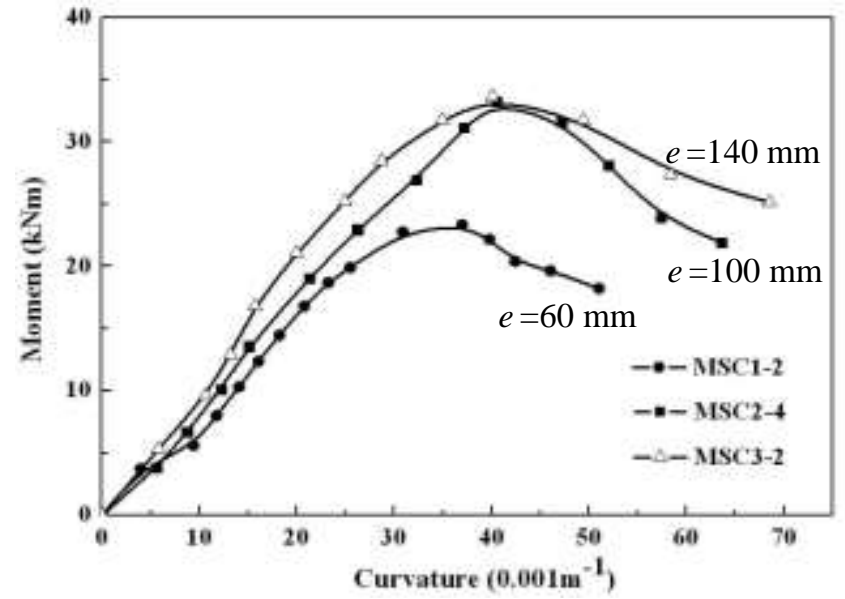

(a)

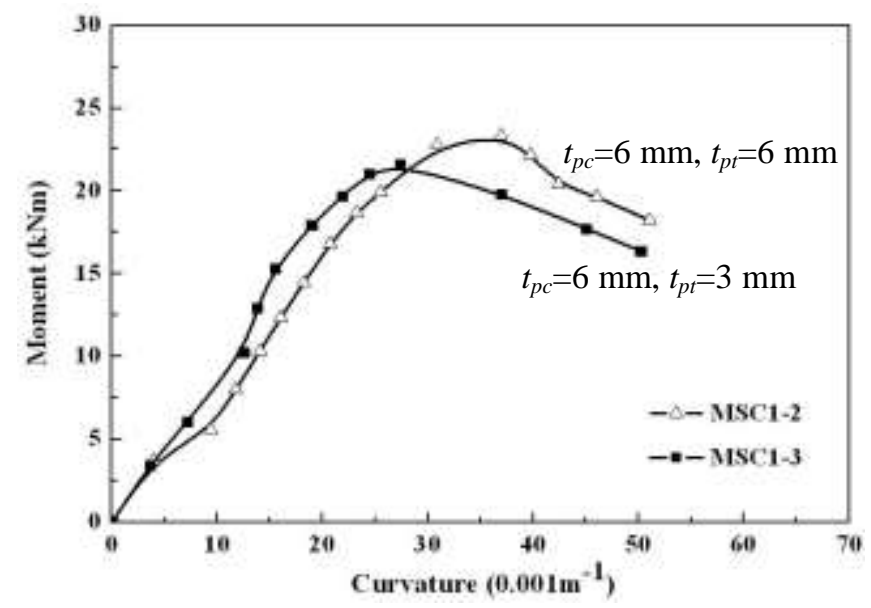

(c)

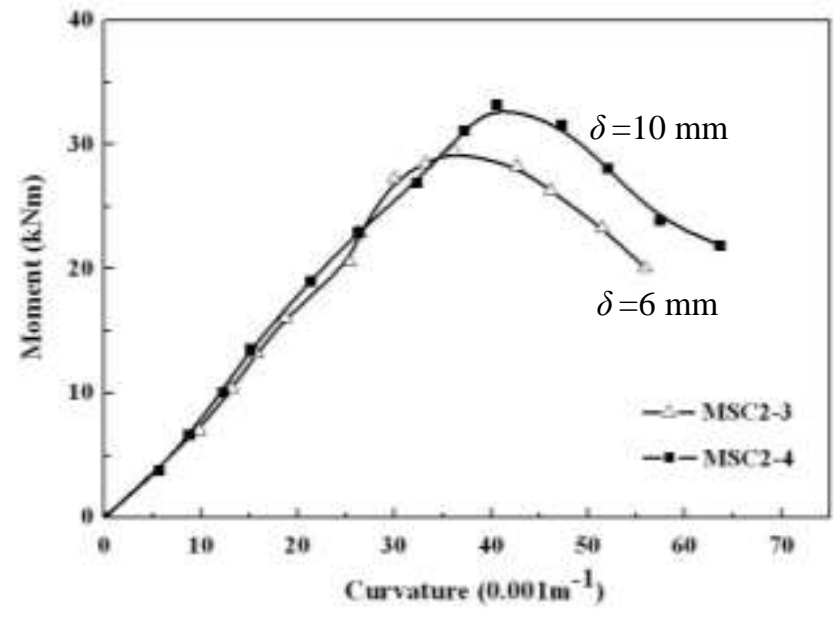

(b)

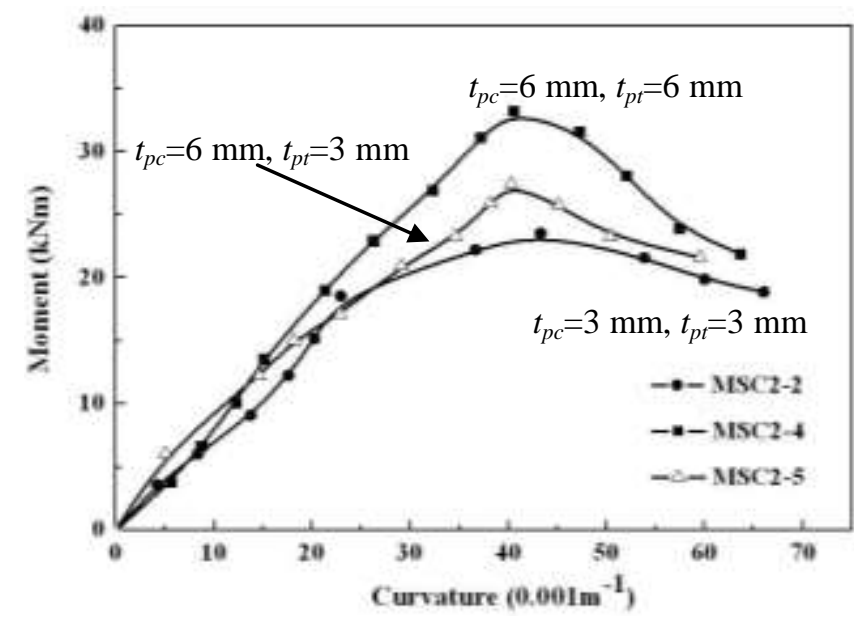

(d)

Figure 15. Moment-curvature responses of columns: (a) $t_{p c}=6 \mathrm{~mm}, t_{p t}=6 \mathrm{~mm}, \delta=10 \mathrm{~mm}$; (b) $t_{p c}=6$ $\mathrm{mm}, t_{p t}=6 \mathrm{~mm}, e=100 \mathrm{~mm}$; (c) $e=60 \mathrm{~mm}, \delta=10 \mathrm{~mm} ;$ (d) $e=100 \mathrm{~mm}, \delta=10 \mathrm{~mm}$ 